\title{
A cross-country study of skills and unemployment flows
}

\author{
Damir Stijepic ${ }^{*}$ (D)
}

\begin{abstract}
Using an international survey that directly assesses the cognitive skills of the adult population, I study the relation between skills and unemployment flows across 37 countries. Depending on the specifically assessed domain, I document that skills have an unconditional correlation with the log-risk-ratio of exiting to entering unemployment of $0.65-0.68$ across the advanced and skill-abundant countries in the sample. The relation is remarkably robust and it is unlikely to be due to reverse causality. I do not find evidence that this positive relation extends to the seven relatively less advanced and less skill-abundant countries in the sample: Peru, Ecuador, Indonesia, Mexico, Chile, Turkey and Kazakhstan.
\end{abstract}

Keywords: Gross worker flows, Unemployment, Skills, Education, Human capital, International comparisons, Survey of Adult Skills, PIAAC

JEL: J20, J24, J60, J64, 120

\section{Introduction}

At least since the human-investment revolution in economic thought in the 1960s (Bowman 1966), human capital is regarded as a key factor in production. Most activities in modern knowledge economies require a certain set of skills, supposedly making the acquisition of the relevant skills a prerequisite for a successful participation in the labor market. In the present paper, I assess the empirical content of this hypothesis by investigating to what extent the skills of a country's labor force foster employment and prevent unemployment.

Human capital is a complex construct. Since the seminal contributions to the human-capital literature by Becker (1964) and by Mincer (1974), years of schooling has remained the predominant measure of human capital. However, conceptual and qualitative differences in educational systems make international comparisons challenging. The contribution of an additional year of schooling to the skills of the students in one country may very well differ from that in another country.

${ }^{*}$ Correspondence: mail@damir.stijepic.com

Johannes Gutenberg University, Mainz, Germany
Furthermore, while an important role of formal education is to add to the productivity of the students through the formation of skills, some scholars stress the role of education as a signaling device for the productive capacities of applicants or as a rationing device for high-status jobs (Spence 1973; Collins 1979).

Achievement tests as a measure of human capital are gaining popularity due to improvements in testing techniques and a broader availability. My analysis is based on the Survey of Adult Skills of the Programme for the International Assessment of Adult Competencies (PIAAC), which is an international survey that directly assesses the cognitive skills of the adult population in a growing number of countries. Therefore, I have highly internationally comparable data on key skills in addition to the traditional measures of human capital, e.g., years spent in education.

Across the 30 advanced and skill-abundant countries in the sample, I document that skills have a pronounced unconditional correlation with the log-risk-ratio of exiting to entering unemployment irrespective of the specific domain: 0.65 for literacy and 0.68 for numeracy. In contrast, formal education as measured by years of schooling 
has a modest unconditional correlation with the logrisk-ratio of 0.26 . In the multivariate analysis with various country characteristics, cognitive skills remain a key source of the international differences in unemployment flows. The instrumental-variable estimates do not suggest that reverse causality leads to a first-order upward bias. I do not find evidence that the positive relation between skills and the log-risk-ratio of exiting to entering unemployment extends to the seven relatively less advanced and less skill-abundant countries in the sample: Peru, Ecuador, Indonesia, Mexico, Chile, Turkey and Kazakhstan.

This paper is structured as follows. In Sect. 2, I review the related literature. I introduce the data and the econometric model in Sect. 3. This paper's main findings on international differences in skills and unemployment flows are in Sect. 4. The individual-level analysis of the relation between skills and the risks of entering and exiting unemployment is in Sect. 5. Section 6 draws some conclusions. Further data details and auxiliary results are in the Appendix.

\section{Related literature}

A large and influential body of literature studies how skills contribute to an individual's success in life. Heckman and Kautz (2012) review the evidence on how school grades, the performance in achievement and IQ tests, personality traits and attitudes relate to success in life. Hanushek and Woessmann (2011) discuss the advantages and challenges of the cross-country comparative approach that makes use of international achievement tests in order to analyze the determinants and effects of cognitive skills. Large international comparisons of the effects of skills among the adult population typically focus on the wage premium (e.g., Hanushek et al. 2015; Leuven et al. 2004). Unemployment is only taken into account insofar as it induces a selection bias in the wage regressions. A recent exception is Stijepic (2020a), who documents that an individual's cognitive skills are positively associated with the probability of being employed in all of the 32 studied countries. ${ }^{1}$

The cited contributions to the literature analyze the individual-level effects of skills. ${ }^{2}$ In contrast, I construct aggregate data in order to study the aggregate-level effects of skills. Hidalgo-Cabrillana et al. (2017) similarly

\footnotetext{
${ }^{1}$ See also Iversen and Strøm (2020).

2 The social returns can be quite different from the private returns to human capital. For instance, entrepreneurs may choose to acquire further skills in order to be more likely to succeed, reducing their probability of becoming unemployed. Provided that entrepreneurs create new job opportunities for others if they succeed, there are positive employment externalities.
}

make use of the PIAAC data in order to explain international differences in macroeconomic variables. Specifically, they show that differences in physical capital together with a multidimensional measure of human capital account for $42 \%$ of the variance across countries in the gross domestic product per capita, stressing the role of cognitive skills. My findings suggest that a potentially quantitatively important channel through which cognitive skills affect international differences in income is the capacity utilization of the factor labor, i.e., the lack of labor underutilization in the form of unemployment. Furthermore, the employment effects of skills are of interest beyond the direct labor-income effects. A large and prominent body of literature documents the impact of displacement and employment breaks on various life outcomes including divorce, criminality, mental health and physical health (e.g., Eliason 2012; Fougère et al. 2009; Kuhn et al. 2009; Sullivan and von Wachter 2009).

Another related strand of the literature studies how a country's unemployment rate is affected by its institutions including social security, employment protection, minimum wage, unionization and product market regulation (see, e.g., Nickell and Layard 1999; Belot and van Ours 2004; Arpaia and Mourre 2012; Boeri et al. 2012; Launov and Wälde 2016). I complement the literature by documenting the close relation between average skill levels and unemployment flows across countries. The individual-level evidence suggests that a more skilled person is more likely to become and to stay employed. However, the skills of a country's labor force may also enhance institutions that prevent inefficient unemployment or generate employment by fostering economic growth. Indeed, the empirical evidence suggests a strong positive impact of cognitive skills on macroeconomic growth (see, e.g., Hanushek and Kimko 2000; Hanushek and Woessmann 2008, 2012). Furthermore, the literature stresses the importance of institutions for long-run growth (see, e.g., Acemoglu et al. 2001, 2005). The question of whether unemployment is potentially a cause or a consequence of weak economic growth is outside the present paper's scope.

By exploiting the available data on unemployment duration, I obtain estimates of the flow rates into and out of unemployment and, hence, the extent of labor reallocation. A related strand of the literature studies the link between the flexibility or sclerosis of labor markets and the level of unemployment (e.g., Blanchard and Summers 1986; Bertola and Rogerson 1997; Blanchard and Portugal 2001). ${ }^{3}$ The literature addresses in particular the

\footnotetext{
${ }^{3}$ In related work, I study the impact of skills on job mobility (Stijepic 2020b), the trends and cycles in job mobility (Stijepic 2021), and the impact of differences between employers on labor-market outcomes (Stijepic 2016, 2017, 2019).
} 
role of institutions, which determine, e.g., the degree of employment protection.

\section{Data and econometric model}

The following empirical analysis is based on the Survey of Adult Skills of the Programme for the International Assessment of Adult Competencies (PIAAC). The PIAAC is a large-scale initiative of the Organization for Economic Cooperation and Development (OECD), providing internationally comparable data on key skills of the adult population in the countries surveyed. ${ }^{4}$ During the first round in 2011-2012, 24 countries participated in the data collection; of these, the following 23 are covered in my analysis: Austria, Belgium (specifically Flanders), Canada, Cyprus, Czechia, Denmark, Estonia, Finland, France, Germany, Ireland, Italy, Japan, the Republic of Korea, the Netherlands, Norway, Poland, Russia (excluding the Moscow municipal area), Slovakia, Spain, Sweden, the United Kingdom (specifically England and Northern Ireland) and the United States. ${ }^{5}$ Another nine countries participated in the second round in 2014-2015: Chile, Greece, Indonesia (specifically Jakarta), Israel, Lithuania, New Zealand, Singapore, Slovenia and Turkey. The third round in 2017 covers five countries additionally: Ecuador, Hungary, Kazakhstan, Mexico and Peru. I do report results for Russia. However, other studies (e.g., Hanushek et al. 2015) do not use the data for Russia given that, among other things, any statistics are potentially biased by the omission of the capital region.

The Survey of Adult Skills measures key cognitive skills that are essential for participation in the labor market and in society. In contrast to IQ tests, the PIAAC achievement tests measure general knowledge that can be acquired in schools and through life experiences. The cognitive assessment is supplemented with a questionnaire that collects a wide variety of background information including demographic, social, educational and economic variables. In each country, a representative sample of adults ages 16-65 is interviewed at home. The standard survey mode is to answer questions on a computer, but a pencil-and-paper interview option also exists for respondents who are not computer literate. The countries use different sampling schemes in selecting their samples, but the samples are all aligned to known population counts with post-sampling weightings. I employ these weights in all calculations, giving

\footnotetext{
${ }^{4}$ See the OECD (2016) technical report for further information on the PIAAC.

${ }^{5}$ Australia is not included since its public-use file is not directly accessible over the OECD website.
}

the same weight to each country in the pooled international sample.

The sample selection is as follows. First, I only study survey participants who report to be unemployed or to be engaged in paid work since transitions into and out of the labor force or non-profit activities may be partially affected by non-market considerations. Second, only respondents ages $25-54$ may enter the final sample. Therefore, I abstract from the peculiarities of the early and late stages of working life. ${ }^{6}$ The final sample encompasses 117,183 individuals with 1512-13,691 observations per country.

\subsection{The ins and outs of unemployment}

Similar to Shimer (2012), I make use of the number of employed, unemployed and short-term unemployed workers in order to identify the entry rate into and the exit rate from unemployment. I classify survey participants as employed if they are engaged in paid work or if they are temporarily away from a job or business to which they plan to return. In particular, a person who is working for a family business without pay is not employed according to this classification. However, a person on parental leave is classified as employed. Survey participants are unemployed if they are not engaged in paid or unpaid work, if they are looking for paid work, and if they are able to start a new job within two weeks. I prefer the classification based on observed behavior, rather than the subjective self-assessed classification which is more prone to cultural influences. However, I note that this definition of unemployment excludes some people, such as discouraged workers who want to work but are not looking for jobs because they do not expect to succeed in their search efforts. Finally, I categorize respondents as short-term unemployed if they had paid work in the preceding twelve months. All other unemployed survey participants are long-term unemployed.

Figure 1 displays the unemployment rate by country. The unemployment rate is $6.4 \%$ in the pooled international sample, ranging from $2.2 \%$ in Belgium to $20.3 \%$ in Greece. In the international sample, there is an approximately equal share of short-term and long-term unemployed individuals, i.e., $3.0 \%$ and $3.3 \%$, respectively. The short-term unemployment rate ranges from 1.3 in Belgium to 8.7 in Spain. The long-term unemployment rate ranges from 0.9 in Belgium to $14.6 \%$ in Greece. I note that the statistics reflect the situation in 2011-2012, 2014-2015 or 2017 depending on the round of data collection. Since many

\footnotetext{
${ }^{6}$ Furthermore, most individuals complete their formal education by the age of 25 .
} 


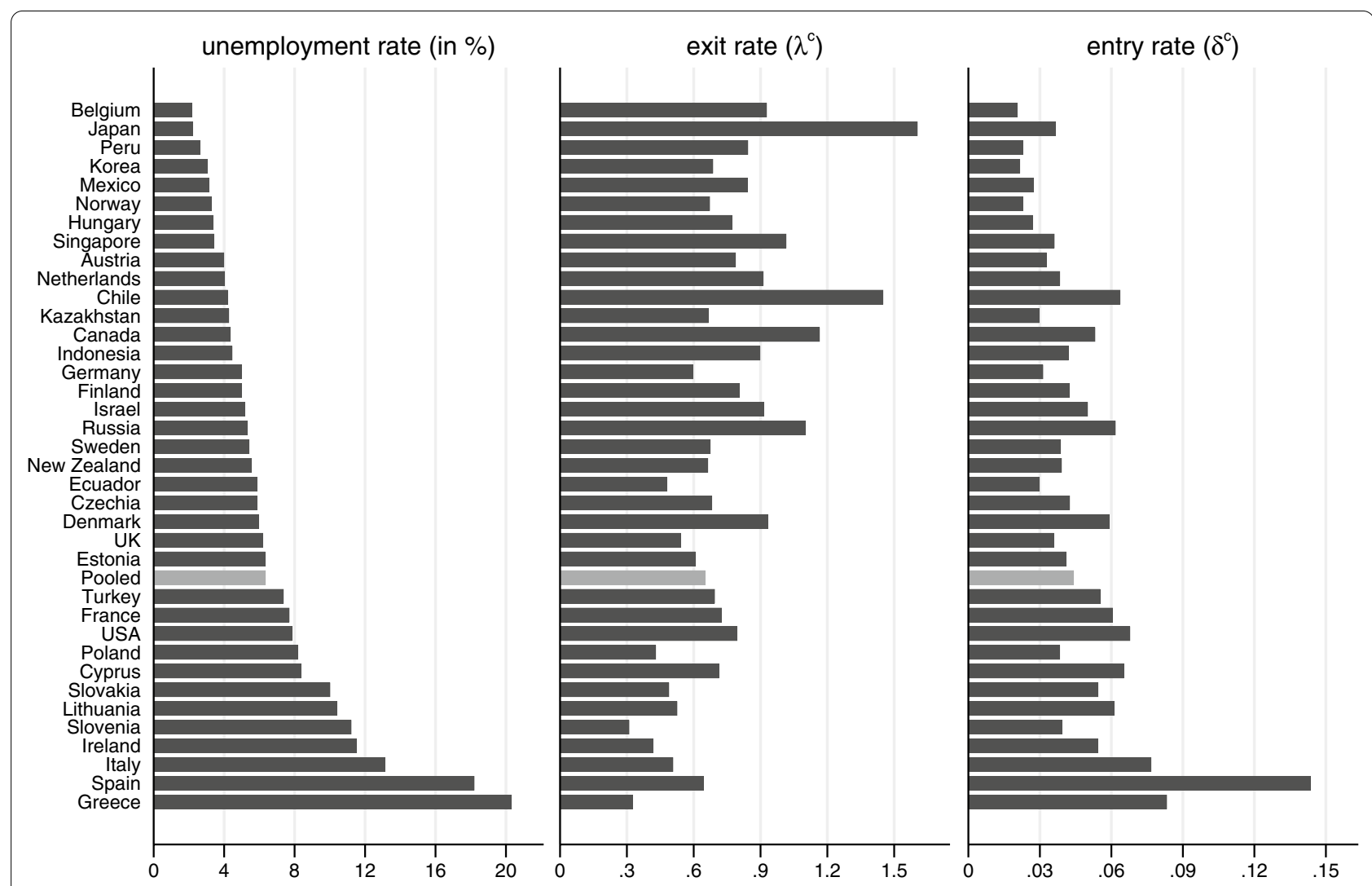

Fig. 1 Unemployment rate, maximum-likelihood estimates of the exit rate from unemployment, $\lambda^{c}$, and of the entry rate into unemployment, $\delta^{c}$, by country. Sample restricted to survey participants ages $25-54$. Sampling weights employed in all calculations, giving the same weight to each country in the pooled specification. Author's calculations based on the Survey of Adult Skills (PIAAC)

countries experienced a pronounced surge in the unemployment rate in the aftermath of the Great Recession, time effects are substantial potentially. Therefore, I take into account fixed effects by round of data collection in the following regressions.

In order to motivate the likelihood function on which the following empirical analysis is based, I rely on a simple search model. Let $s_{t}$ denote the employment status of a worker in the year $t$. Workers are either employed, $s=e$, or unemployed, $s=u$. Unemployed workers become employed at a rate of $\lambda>0$ and employed workers become unemployed at a rate of $\delta>0$. The probabilities of observing a long-term unemployed worker, $s=u_{l}$, and a short-term unemployed worker, $s=u_{s}$, in a random sample in the year $t+1$ are

$$
\begin{aligned}
P\left(s_{t+1}=\right. & \left.u_{l}\right) \\
& =P\left(s_{t+1}=u \mid \forall \tau \in[t, t+1): s_{\tau}=u\right) \\
& =\mathrm{e}^{-\lambda} \mathrm{P}\left(\mathrm{s}_{\mathrm{t}}=\mathrm{u}\right) \text { and }
\end{aligned}
$$

$$
\begin{aligned}
P\left(s_{t+1}=\right. & \left.u_{s}\right) \\
& =P\left(s_{t+1}=u \mid \exists \tau \in[t, t+1): s_{\tau}=e\right) \\
& =P\left(s_{t+1}=u\right)-P\left(s_{t+1}=u_{l}\right) \\
& =P\left(s_{t+1}=u\right)-\mathrm{e}^{-\lambda} P\left(s_{t}=u\right),
\end{aligned}
$$

respectively, where $P(\cdot)$ denotes the probability of the respective event.

In the steady state, the flow of employed workers into unemployment equals the flow of unemployed workers into employment. Hence, the steady-state probabilities of observing an employed and an unemployed worker are $P(s=e)=\lambda /(\delta+\lambda)$ and $P(s=u)=\delta /(\delta+\lambda)$, respectively. Hence, by Eqs. (1) and (2), the steady-state probability distribution is

$$
\begin{gathered}
P(s)=\frac{\lambda}{\delta+\lambda} \text { if } s=e, \frac{\delta}{\delta+\lambda}\left(1-\mathrm{e}^{-\lambda}\right) \\
\text { if } s=u_{s}, \text { and } \frac{\delta}{\delta+\lambda} \mathrm{e}^{-\lambda} \text { if } \mathrm{s}=\mathrm{u}_{\mathrm{l}} .
\end{gathered}
$$

Finally, I assume the effects of the various covariates, denoted by $x_{i}$ for $i \in\{1, \ldots, n\}$, on the flow rates into and out of unemployment to be log-linear, i.e., 
$\delta=\exp \left(\delta_{0}+\sum_{i=1}^{n} \delta_{i} x_{i}\right)$ and $\lambda=\exp \left(\lambda_{0}+\sum_{i=1}^{n} \lambda_{i} x_{i}\right)$. In order to derive the likelihood function in Eq. (3), I impose that unemployment is at its steady-state level. I relax this assumption in the Appendix.

In a first exercise based on the function in Eq. (3), I estimate by maximum likelihood the parameters $\lambda_{0}$ and $\delta_{0}$ for each country, not taking into account any covariate effects, i.e., $\lambda_{i}=\delta_{i}=0$ for all $i=1, \ldots, n$. Let these country-level estimates be denoted by $\lambda_{0}^{c}$ and $\delta_{0}^{c}$, where $c$ is the country index. Figure 1 displays the implied exit rate from unemployment, $\lambda^{c}$, and the entry rate into unemployment, $\delta^{c}$, by country. In the pooled international sample, the exit rate from and the entry rate into unemployment are 0.652 and 0.044 , implying an average unemployment-spell and employment-spell duration of 1.5 years and 22.7 years, respectively. I note that I distinguish individuals who have been unemployed for less than a year and individuals who have been unemployed for at least a year in order to identify the exit rate from unemployment. However, the variation in shorter unemployment spells tends to imply higher transition rates. Indeed, numerous studies document the negative duration dependence in the exit rate from unemployment for some countries (see, e.g., Kaitz 1970; Elsby et al. 2013). In the Appendix, I also exploit the variation in shorter unemployment spells in order to obtain estimates of the transition rates. ${ }^{7}$

In the model, the ratio of the exit rate from to the entry rate into unemployment coincides with the ratio of employed workers, $\lambda^{c} /\left(\delta^{c}+\lambda^{c}\right)$, to unemployed workers, $\delta^{c} /\left(\delta^{c}+\lambda^{c}\right)$. Indeed, the estimation procedure constrains the ratio of the exit to the entry rate to exactly match the ratio of employed to unemployed workers and, hence, the unemployment rate in the sample. Under the stated model assumptions, explaining country differences in the ratio of the exit to the entry rate or country differences in the ratio of employed to unemployed workers is the same task. In that sense, the latter interpretation of country differences does not rely on specific structural assumptions. However, the estimated absolute magnitudes of the entry and exit rates are to be more narrowly interpreted within the theoretical framework.

Notably, some countries substantially differ in the estimated exit and entry rates despite similar unemployment rates. For instance, both Greece and Spain face an unemployment rate of $18-20 \%$. On the one hand, the exit rate and the entry rate in Greece are 0.327 and 0.083 , respectively. On the other hand, the rates in Spain are 0.645

\footnotetext{
7 The respective questionnaire items relating to unemployment duration are not available in the Canadian and U.S. public-use files.

8 Spain is among those economies of the European Union that most decidedly promoted temporary-employment contracts in the past, with temporary employment reaching up to one-third of salaried employees. Bentolila et al. (2012) argue that Spain could have avoided about $45 \%$ of its unem-
}

and 0.144 , respectively. This reflects the difference in the shares of long-term unemployed individuals, which are $14.6 \%$ and $9.6 \%$ in Greece and in Spain, respectively. ${ }^{8}$

\subsection{Covariates}

The PIAAC measures the cognitive skills of the survey participants in three domains: numeracy, literacy and problem solving in technology-rich environments. However, the assessment of problem-solving skills is not carried out in all countries and among all survey participants in a country. The PIAAC defines literacy as "understanding, evaluating, using and engaging with written texts to participate in society, to achieve one's goals, and to develop one's knowledge and potential," while numeracy is defined as "the ability to access, use, interpret and communicate mathematical information and ideas, in order to engage in and manage the mathematical demands of a range of situations in adult life." The PIAAC measures literacy and numeracy on a 500-point scale. ${ }^{9}$ In the pooled international sample, the average of the literacy score and of the numeracy score are 267 and 265, the standard deviations being 53 and 57, respectively. For the estimations in this study, I standardize the scores to obtain a mean of zero and a standard deviation of one in the pooled international sample in order to facilitate the interpretation. Following Hanushek et al. (2017), I focus on numeracy skills, which are most comparable across countries supposedly.

Figure 2 depicts the relation across countries between the estimated risk ratio of exiting to entering unemployment, $\lambda^{c} / \delta^{c}$, and the average skill scores. Across the 37 countries in the sample, the numeracy and literacy scores have a limited correlation with the logarithmized risk ratio of exiting to entering unemployment of 0.01 . The associated ordinary least-squares lines explain less than $1 \%$ of the variance across countries in the logarithmized risk ratio. However, allowing for a single optimal break point in the intercept and slope coefficients of the ordinary least-squares regression, the explained variance increases to $48 \%$ and $44 \%$, respectively. Figure 2 shows the ordinary least-squares lines with the optimal break points. The regression analysis implies the same optimal division of the 37 countries irrespective of the specific skill domain: a group of seven relatively skillscarce economies, i.e., Indonesia, Ecuador, Peru, Mexico,

\footnotetext{
Footnote 8 (continued)

ployment surge in the aftermath of the Great Recession if it had adopted the French employment-protection legislation.

9 Throughout this paper, I use the first plausible PIAAC-score values in each domain.
} 


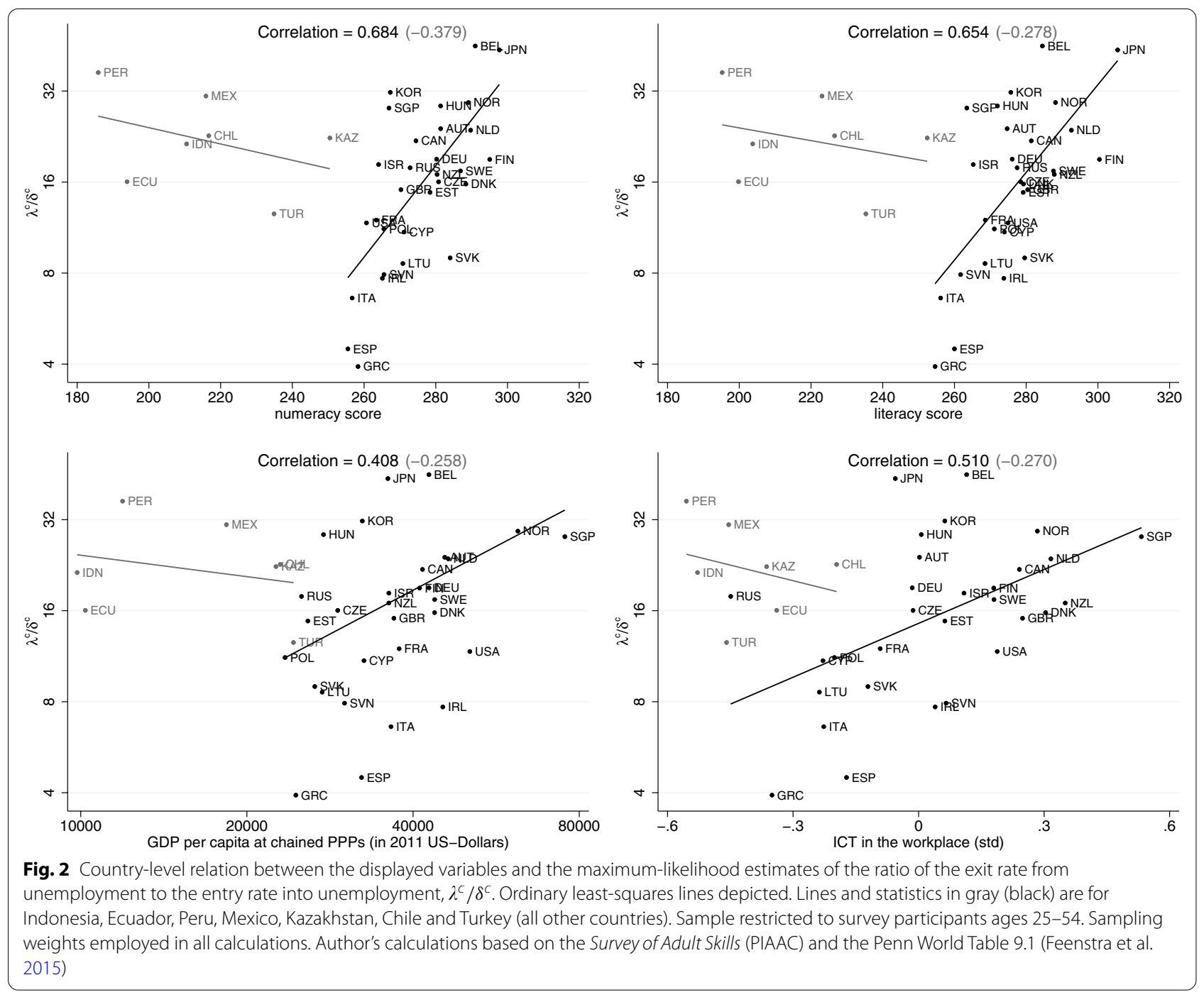

Kazakhstan, Chile and Turkey, and a group of 30 relatively skill-abundant economies.

Notably, the seven skill-scarce economies, i.e., Indonesia, Ecuador, Peru, Mexico, Kazakhstan, Chile and Turkey, exhibit substantially lower average skill levels compared to the other countries in the sample. Specifically, the average numeracy score among the other 30 countries is 275 with a between-country standard deviation of twelve. The seven skill-scarce countries have average numeracy scores that are 2.1-7.5 standard deviations below that average. Similarly, the average literacy score among the 30 skill-abundant countries is 276 with a between-country standard deviation of twelve. The seven skill-scarce countries have average literacy scores that are 2.0-6.9 standard deviations below that average. All in all, the seven skill-scarce countries have starkly lower skill levels and the relation of skills with the ins and outs of unemployment seems to be qualitatively different.
Therefore, the skill-scarce and skill-abundant countries warrant a separate analysis. In particular, I focus on the skill-abundant countries in the main analysis since the sample of skill-scarce countries is small.

I assess the proximity of an economy to the technology frontier by the average use of information and communication technology (ICT) in the workplace. The measure of ICT use at work is based on how often the survey participants usually "use email", "use the internet in order to better understand issues related to [their] work", "conduct transactions on the internet, for example buying or selling products or services, or banking", "use spreadsheet software, for example Excel", "use a word processor, for example Word", "use a programming language to program or write computer code", or "participate in real-time discussion on the internet, for example online conference, or chat groups" in their job, where the five answer categories range from "Never" to "Every day." The scale 
for ICT use is constructed according to item-response theory: the item parameters are estimated using the generalized partial-credit model and the person-specific levels of ICT use are estimated using the weighted-likelihood method. I assign a value of zero for ICT use if a person indicates never pursuing any of the stated activities or not using a computer on the job. In order to facilitate the interpretation, I standardize the measure of ICT use to obtain a mean of zero and a standard deviation of one in the pooled international sample. Figure 2 depicts the relation across countries between the risk ratio of exiting to entering unemployment and the average use of ICT in the workplace. Notably, the seven skill-scarce countries are among the countries with the lowest average use of ICT in the workplace.

Making use of the Penn World Table version 9.1 (Feenstra et al. 2015), I measure the economic advancement of countries by the gross domestic product (GDP) per capita at purchasing-power-parities (PPP) exchange rates in 2011 US-Dollars. Figure 2 depicts the cross-country relation between the risk ratio of exiting to entering unemployment and GDP per capita. Notably, the seven skill-scarce countries are among the countries with the lowest GDP per capita. Furthermore, making use of the databases of the OECD and the International Labour Organization (ILO), I also consider key institutional characteristics of the labor markets as explanatory factors: the minimum wage relative to the median wage, employment protection as measured by the strictness of the regulations relating to the dismissal of workers with regular contracts (regular), employment protection as measured by the restriction of temporary work and fixed-term contracts (temporary), trade union density as measured by the share of employees who are union members, unemployment benefits as measured by the net replacement rate during the second month of unemployment for a single person who earned 67 percent of the average wage (level), and unemployment benefits as measured by the difference in the net replacement rates between the second month and the 14th month of unemployment (degression). ${ }^{10}$

\section{Country-level evidence}

In order to obtain estimates of the impact of skills on unemployment flows at the country level, I choose a two-step estimation procedure. In the first step, I maximize the likelihood function in Eq. (3) in order to obtain estimates of the parameters $\lambda_{0}^{c}$ and $\delta_{0}^{c}$ for each country $c$. I do not take into account any covariate effects at this step, i.e., $\lambda_{i}=\delta_{i}=0$ for all $i=1, \ldots, n$. Furthermore,

\footnotetext{
${ }^{10}$ Accessed at https://stats.oecd.org/ (OECD database) and at https://ilostat. ilo.org/data/ (ILO database) on December 20, 2020.
}

I also compute country averages of the covariates of interest, e.g., the numeracy score. Let the country averages of the respective covariates be denoted by $x_{i}^{c}$. In the second step, I simultaneously regress the estimated logrisks $\lambda_{0}^{c}$ and $\delta_{0}^{c}$ on a set of country averages of the covariates of interest in a seemingly unrelated regressions (SUR) setup à la Zellner (1962). Specifically, the system of econometric equations is

$$
\begin{aligned}
& \lambda_{0}^{c}=\lambda_{0}+\sum_{i=1}^{n} \lambda_{i} x_{i}^{c}+\epsilon_{\lambda}^{c} \text { and } \\
& \delta_{0}^{c}=\delta_{0}+\sum_{i=1}^{n} \delta_{i} x_{i}^{c}+\epsilon_{\delta}^{c},
\end{aligned}
$$

where $\epsilon_{\lambda}^{c}$ and $\epsilon_{\delta}^{c}$ denote the unexplained residuals.

Table 1 displays estimates of the parameters $\lambda_{i}$ and $\delta_{i}$ for the baseline sample excluding Indonesia, Ecuador, Peru, Mexico, Kazakhstan, Chile and Turkey. Specifications (1)-(5) present a first series of SUR estimates for different sets of control variables. Specification (1) effectively replicates the bivariate scatter plot in Fig. 2, additionally controlling for fixed effects by round of data collection. A one-standard-deviation increase in numeracy skills is associated with an increase in the exit rate from unemployment and with a decrease in the entry rate into unemployment by a factor of $2.2(\exp (0.777))$ and by a factor of $0.3(\exp (-1.193))$, respectively. Hence, the risk ratio of exiting to entering unemployment rises by a factor of $7.2(\exp (0.777+1.193))$. The average numeracy score ranges from 255 in Spain to 298 in Japan. Evaluated at this range, the estimates suggest an increase in the ratio of employed to unemployed workers by a factor of $4.3(\exp ((1.969 / 57)(298-255)))$, corresponding to a fall in the unemployment rate from 18.2 to $5.0 \%$ in the case of Spain.

The more comprehensive multivariate specifications (2)-(5) in Table 1 paint a similar picture. Numeracy skills remain a key determinant of the international differences in unemployment flows. Depending on the set of additional controls, a one-standard-deviation increase in numeracy skills is estimated to raise the risk ratio of exiting to entering unemployment by a factor of 5.7-9.5. A larger public sector is associated with a lower risk ratio of exiting to entering unemployment. A higher minimum wage is estimated to raise employment, mainly by lowering the entry rate into unemployment. More generouseither higher or less degressive-unemployment benefits are associated with a higher entry rate into unemployment. The level of the unemployment benefits is positively correlated with the exit rate from unemployment. I note that I do not control for composition effects, which may be relevant given the positive association between 
Table 1 Country-level estimates of the effects of the displayed variables on the risks of exiting unemployment and of entering unemployment in a seemingly unrelated regressions setup à la Zellner (1962)

\begin{tabular}{|c|c|c|c|c|c|c|c|}
\hline & \multicolumn{5}{|l|}{ SUR } & \multicolumn{2}{|l|}{ GMM } \\
\hline & $(1)$ & (2) & (3) & (4) & $(5)$ & (6) & $(7)$ \\
\hline & \multicolumn{7}{|c|}{$\lambda_{j}$ (log-risk of exiting unemployment) } \\
\hline \multirow[t]{2}{*}{ Numeracy (std) } & $0.777^{* * *}$ & $0.766^{* *}$ & $0.849 * * *$ & $0.777^{* * *}$ & $1.018^{* * *}$ & $0.807^{* *}$ & 0.281 \\
\hline & $(0.297)$ & $(0.312)$ & $(0.318)$ & $(0.288)$ & $(0.296)$ & $(0.385)$ & $(0.711)$ \\
\hline \multirow[t]{2}{*}{ Logarithmized GDP per capita (PPP) } & - & $0.507^{*}$ & - & - & $0.614^{*}$ & 0.540 & 0.356 \\
\hline & & $(0.306)$ & & & $(0.315)$ & $(0.329)$ & $(0.413)$ \\
\hline \multirow[t]{2}{*}{ Employment in public sector (share) } & - & -0.920 & - & - & $-2.137^{* *}$ & $-2.227^{* *}$ & $-2.451^{* *}$ \\
\hline & & $(0.912)$ & & & $(1.090)$ & $(1.105)$ & $(1.238)$ \\
\hline \multirow[t]{2}{*}{ ICT in the workplace (std) } & - & -0.180 & - & - & -0.164 & -0.012 & 0.365 \\
\hline & & $(0.394)$ & & & $(0.456)$ & $(0.492)$ & $(0.679)$ \\
\hline \multirow[t]{2}{*}{ Minimum relative to median wage } & - & - & -0.586 & - & 0.397 & 0.168 & -0.400 \\
\hline & & & $(1.038)$ & & $(0.945)$ & $(0.989)$ & $(1.250)$ \\
\hline \multirow[t]{2}{*}{ Trade union density } & - & - & -0.163 & - & -0.101 & -0.066 & 0.020 \\
\hline & & & $(0.443)$ & & $(0.441)$ & $(0.446)$ & $(0.499)$ \\
\hline \multirow[t]{2}{*}{ Unemployment benefits (level) } & - & - & - & $0.883^{*}$ & $0.965^{*}$ & $1.038^{*}$ & $1.219^{*}$ \\
\hline & & & & $(0.490)$ & $(0.552)$ & $(0.564)$ & $(0.650)$ \\
\hline \multirow[t]{2}{*}{ Unemployment benefits (degression) } & - & - & - & 0.129 & 0.228 & 0.114 & -0.168 \\
\hline & & & & $(0.342)$ & $(0.383)$ & $(0.408)$ & $(0.543)$ \\
\hline \multirow[t]{2}{*}{ Employment protection (regular) } & - & - & - & -0.179 & $-0.220^{* *}$ & -0.189 & -0.113 \\
\hline & & & & $(0.117)$ & $(0.111)$ & $(0.117)$ & $(0.153)$ \\
\hline \multirow[t]{2}{*}{ Employment protection (temporary) } & - & - & - & -0.065 & -0.007 & -0.013 & -0.027 \\
\hline & & & & $(0.072)$ & $(0.073)$ & $(0.074)$ & $(0.083)$ \\
\hline \multirow[t]{2}{*}{ Instrument for numeracy } & - & - & - & - & - & numeracy & PISA \\
\hline & & & & & & ages 16-19 & math \\
\hline$R^{2}\left(\lambda_{0}^{c}\right)$ & 0.246 & 0.366 & 0.279 & 0.514 & 0.667 & 0.660 & 0.590 \\
\hline \multirow[t]{2}{*}{ Observations } & 30 & 30 & 29 & 27 & 27 & 27 & 27 \\
\hline & $\delta_{i}(\log$-risk & tering unen & yment) & & & & \\
\hline \multirow[t]{2}{*}{ Numeracy (std) } & $-1.193^{* * *}$ & $-0.982^{* * *}$ & $-1.321^{* * *}$ & $-1.224^{* * *}$ & $-1.231^{* * *}$ & $-1.575^{* * *}$ & $-2.144^{* *}$ \\
\hline & $(0.317)$ & $(0.336)$ & $(0.340)$ & $(0.382)$ & $(0.389)$ & $(0.509)$ & $(0.926)$ \\
\hline \multirow[t]{2}{*}{ Logarithmized GDP per capita (PPP) } & - & 0.076 & - & - & -0.203 & -0.323 & -0.521 \\
\hline & & $(0.329)$ & & & $(0.414)$ & $(0.434)$ & $(0.537)$ \\
\hline \multirow[t]{2}{*}{ Employment in public sector (share) } & - & 0.883 & - & - & 1.755 & 1.608 & 1.367 \\
\hline & & $(0.983)$ & & & $(1.433)$ & $(1.460)$ & $(1.611)$ \\
\hline \multirow[t]{2}{*}{ ICT in the workplace (std) } & - & -0.620 & - & - & $-1.205^{* *}$ & -0.958 & -0.550 \\
\hline & & $(0.424)$ & & & $(0.600)$ & $(0.650)$ & $(0.883)$ \\
\hline \multirow[t]{2}{*}{ Minimum relative to median wage } & - & - & -1.455 & - & $-2.671^{* *}$ & $-3.042^{* *}$ & $-3.657^{* *}$ \\
\hline & & & $(1.112)$ & & $(1.242)$ & $(1.307)$ & $(1.626)$ \\
\hline \multirow[t]{2}{*}{ Trade union density } & - & - & 0.528 & - & -0.317 & -0.260 & -0.167 \\
\hline & & & $(0.474)$ & & $(0.579)$ & $(0.590)$ & $(0.650)$ \\
\hline Unemployment benefits (level) & - & - & - & 0.450 & $1.560^{* *}$ & $1.678^{* *}$ & $1.874^{* *}$ \\
\hline & & & & $(0.651)$ & $(0.727)$ & $(0.745)$ & $(0.846)$ \\
\hline Unemployment benefits (degression) & - & - & - & -0.198 & $-1.098^{* *}$ & $-1.283^{* *}$ & $-1.588^{* *}$ \\
\hline & & & & $(0.454)$ & $(0.504)$ & $(0.539)$ & $(0.707)$ \\
\hline Employment protection (regular) & - & - & - & -0.095 & -0.126 & -0.076 & 0.007 \\
\hline & & & & $(0.156)$ & $(0.145)$ & $(0.155)$ & $(0.199)$ \\
\hline Employment protection (temporary) & - & - & - & 0.042 & -0.130 & -0.140 & -0.155 \\
\hline & & & & $(0.095)$ & $(0.096)$ & $(0.098)$ & $(0.107)$ \\
\hline Instrument for numeracy & - & - & - & - & - & numeracy & PISA \\
\hline
\end{tabular}


Table 1 (continued)

\begin{tabular}{|c|c|c|c|c|c|c|c|}
\hline & \multicolumn{5}{|l|}{ SUR } & \multicolumn{2}{|l|}{ GMM } \\
\hline & $(1)$ & (2) & (3) & (4) & $(5)$ & (6) & (7) \\
\hline & & & & & & ages 16-19 & math \\
\hline$R^{2}\left(\delta_{0}^{\complement}\right)$ & 0.361 & 0.451 & 0.410 & 0.395 & 0.593 & 0.581 & 0.510 \\
\hline \multirow[t]{2}{*}{ Observations } & 30 & 30 & 29 & 27 & 27 & 27 & 27 \\
\hline & \multicolumn{7}{|c|}{$\lambda_{i}-\delta_{i}$ (log-risk-ratio of exiting to entering unemployment) } \\
\hline \multirow[t]{2}{*}{ Numeracy (std) } & $1.969^{* * *}$ & $1.748^{* * *}$ & $2.170^{* * *}$ & $2.001^{* * *}$ & $2.249^{* * *}$ & $2.382^{* * *}$ & $2.425^{* * *}$ \\
\hline & $(0.409)$ & $(0.399)$ & $(0.449)$ & $(0.442)$ & $(0.397)$ & $(0.513)$ & $(0.863)$ \\
\hline \multirow[t]{2}{*}{ Logarithmized GDP per capita (PPP) } & - & 0.431 & - & - & $0.816^{*}$ & $0.862^{* *}$ & $0.877^{*}$ \\
\hline & & $(0.392)$ & & & $(0.422)$ & $(0.438)$ & $(0.501)$ \\
\hline \multirow[t]{2}{*}{ Employment in public sector (share) } & - & -1.804 & - & - & $-3.892^{* * *}$ & $-3.835^{* * *}$ & $-3.817^{* *}$ \\
\hline & & $(1.169)$ & & & $(1.461)$ & $(1.471)$ & $(1.502)$ \\
\hline \multirow[t]{2}{*}{ ICT in the workplace (std) } & - & 0.440 & - & - & $1.041^{*}$ & 0.946 & 0.915 \\
\hline & & $(0.504)$ & & & $(0.612)$ & $(0.655)$ & $(0.824)$ \\
\hline \multirow[t]{2}{*}{ Minimum relative to median wage } & - & - & 0.869 & - & $3.068^{* *}$ & $3.211^{* *}$ & $3.257^{* *}$ \\
\hline & & & $(1.465)$ & & $(1.267)$ & $(1.317)$ & $(1.517)$ \\
\hline \multirow[t]{2}{*}{ Trade union density } & - & - & -0.691 & - & 0.216 & 0.194 & 0.187 \\
\hline & & & $(0.624)$ & & $(0.591)$ & $(0.594)$ & $(0.606)$ \\
\hline \multirow[t]{2}{*}{ Unemployment benefits (level) } & - & - & - & 0.433 & -0.595 & -0.640 & -0.655 \\
\hline & & & & $(0.752)$ & $(0.741)$ & $(0.751)$ & $(0.789)$ \\
\hline \multirow[t]{2}{*}{ Unemployment benefits (degression) } & - & - & - & 0.327 & $1.326^{* * *}$ & $1.397^{* *}$ & $1.420^{* *}$ \\
\hline & & & & $(0.525)$ & $(0.514)$ & $(0.543)$ & $(0.659)$ \\
\hline \multirow[t]{2}{*}{ Employment protection (regular) } & - & - & - & -0.084 & -0.094 & -0.113 & -0.119 \\
\hline & & & & $(0.180)$ & $(0.148)$ & $(0.156)$ & $(0.186)$ \\
\hline \multirow[t]{2}{*}{ Employment protection (temporary) } & - & - & - & -0.107 & 0.123 & 0.127 & 0.128 \\
\hline & & & & $(0.110)$ & $(0.098)$ & $(0.098)$ & $(0.100)$ \\
\hline \multirow[t]{2}{*}{ Instrument for numeracy } & - & - & - & - & - & numeracy & PISA \\
\hline & & & & & & ages 16-19 & math \\
\hline$R^{2}\left(\lambda_{0}^{\complement}-\delta_{0}^{\complement}\right)$ & 0.485 & 0.624 & 0.512 & 0.613 & 0.797 & 0.796 & 0.795 \\
\hline Observations & 30 & 30 & 29 & 27 & 27 & 27 & 27 \\
\hline
\end{tabular}

Sample restricted to survey participants ages 25-54 and excluding survey participants from Indonesia, Ecuador, Peru, Mexico, Kazakhstan, Chile and Turkey. Fixed effects by round of data collection not displayed. Set of covariates in specifications (3) and (5)-(7) additionally includes an indicator variable for countries without minimum-wage regulations. Sampling weights employed in all calculations. Standard errors in parentheses. Statistical significance at the 10,5 , and $1 \%$ level denoted by***, and ${ }^{* * *}$, respectively. Author's calculations based on the Survey of Adult Skills (PIAAC), the Penn World Table 9.1 (Feenstra et al. 2015), OECD statistics (https:// stats.oecd.org/) and ILO statistics (https://ilostat.ilo.org/data/)

the benefits level and the entry rate into unemployment. All in all, the correlation between the level of the unemployment benefits and the risk ratio of exiting to entering unemployment is not evidently negative across the studied countries, but a more degressive scheme tends to be positively associated with employment.

Different employment patterns could directly affect skills over the life cycle, leading to biased estimates due to reverse causality. For instance, employment breaks might induce skill depreciation or prevent a person from acquiring certain skills (see, e.g., Edin and Gustavsson 2008). In order to address this challenge to a causal interpretation of the estimated employment effects of skills, I make use of the instrumental-variable method. Specifically, I instrument the skills of the adult population in a country by the respective averages among teenagers ages 16-19 irrespective of whether they are in the labor force or not. Survey participants in this age range are, if at all, at the beginning of their careers, limiting the effect of labor-market outcomes on skills. In particular, the skills of this subgroup rather reflect the skills that are acquired in education during childhood and early adulthood in a country. Specification (6) in Table 1 displays the respective instrumental-variable estimates. The main qualitative conclusions are unaltered. In specification (7), I instrument the skills of the adult population by the average math score that the students obtained in the achievement tests of the Programme for International Student Assessment (PISA) in 2006. ${ }^{11}$ Numeracy skills

${ }^{11}$ Accessed at https://www.oecd.org/pisa/data/ on December 20, 2020. 
Table 2 Country-level estimates of the effects of the displayed variables on the risks of exiting unemployment and of entering unemployment in a seemingly unrelated regressions setup à la Zellner (1962)

\begin{tabular}{|c|c|c|c|c|c|c|c|}
\hline & \multicolumn{6}{|c|}{ Women and men } & \multirow{2}{*}{$\begin{array}{l}\text { Men } \\
\text { (7) }\end{array}$} \\
\hline & (1) & $(2)$ & (3) & (4) & $(5)$ & $(6)$ & \\
\hline & \multicolumn{7}{|c|}{$\lambda_{i}$ (log-risk of exiting unemployment) } \\
\hline \multirow[t]{2}{*}{ Numeracy (std) } & -0.097 & 0.002 & 0.017 & 0.151 & -0.110 & 0.072 & -0.245 \\
\hline & $(0.298)$ & $(0.170)$ & $(0.239)$ & $(0.266)$ & $(0.177)$ & $(0.246)$ & $(0.327)$ \\
\hline \multirow[t]{2}{*}{ × Logarithmized GDP per capita (PPP, demeaned) } & - & - & 0.373 & - & - & -0.218 & $-1.006^{*}$ \\
\hline & & & $(0.272)$ & & & $(0.450)$ & $(0.597)$ \\
\hline \multirow[t]{2}{*}{$\times I C T$ in the workplace $(\mathrm{std})$} & - & - & - & 0.882 & - & 1.098 & $2.066^{*}$ \\
\hline & & & & $(0.596)$ & & $(0.843)$ & $(1.061)$ \\
\hline \multirow[t]{2}{*}{$\times$ Employment in agriculture (share, demeaned) } & - & - & - & - & $-6.251^{* *}$ & -6.196 & $-7.553^{*}$ \\
\hline & & & & & $(3.080)$ & $(4.087)$ & $(4.228)$ \\
\hline \multirow[t]{2}{*}{ Logarithmized GDP per capita (PPP, demeaned) } & - & - & 0.293 & - & - & 0.186 & -0.032 \\
\hline & & & $(0.216)$ & & & $(0.287)$ & $(0.358)$ \\
\hline \multirow[t]{2}{*}{ ICT in the workplace (std) } & - & - & - & 0.185 & - & -0.374 & 0.036 \\
\hline & & & & $(0.289)$ & & $(0.382)$ & $(0.483)$ \\
\hline \multirow[t]{2}{*}{ Employment in agriculture (share, demeaned) } & - & - & - & - & $-9.258^{* * *}$ & $-9.698^{* * *}$ & $-6.506^{* *}$ \\
\hline & & & & & $(2.934)$ & $(3.504)$ & $(3.208)$ \\
\hline$R^{2}\left(\lambda_{0}^{c}\right)$ & 0.294 & 0.005 & 0.080 & 0.082 & 0.217 & 0.273 & 0.272 \\
\hline \multirow[t]{2}{*}{ Observations } & 7 & 37 & 37 & 37 & 37 & 37 & 37 \\
\hline & \multicolumn{7}{|c|}{$\delta_{i}$ (log-risk of entering unemployment) } \\
\hline \multirow[t]{2}{*}{ Numeracy (std) } & 0.176 & $-0.299^{*}$ & $-0.644^{* * *}$ & $-0.522^{* *}$ & $-0.327^{*}$ & $-0.572^{* *}$ & $-0.800^{* * *}$ \\
\hline & $(0.143)$ & $(0.170)$ & $(0.213)$ & $(0.240)$ & $(0.181)$ & $(0.238)$ & $(0.268)$ \\
\hline \multirow[t]{2}{*}{$\times$ Logarithmized GDP per capita (PPP, demeaned) } & - & - & $-0.876^{* * *}$ & - & - & -0.444 & -0.249 \\
\hline & & & $(0.243)$ & & & $(0.436)$ & $(0.489)$ \\
\hline \multirow[t]{2}{*}{$\times \mathrm{ICT}$ in the workplace (std) } & - & - & - & $-1.498^{* * *}$ & - & -0.576 & -1.024 \\
\hline & & & & $(0.537)$ & & $(0.816)$ & $(0.869)$ \\
\hline \multirow[t]{2}{*}{$\times$ Employment in agriculture (share, demeaned) } & - & - & - & - & $8.143^{* * *}$ & 2.454 & 3.534 \\
\hline & & & & & $(3.150)$ & (3.958) & $(3.461)$ \\
\hline \multirow[t]{2}{*}{ Logarithmized GDP per capita (PPP, demeaned) } & - & - & -0.194 & - & - & 0.080 & 0.218 \\
\hline & & & $(0.193)$ & & & $(0.278)$ & $(0.293)$ \\
\hline \multirow[t]{2}{*}{ ICT in the workplace (std) } & - & - & - & -0.387 & - & -0.285 & -0.158 \\
\hline & & & & $(0.261)$ & & $(0.370)$ & $(0.396)$ \\
\hline \multirow[t]{2}{*}{ Employment in agriculture (share, demeaned) } & - & - & - & - & $6.985^{* *}$ & 3.636 & $4.459^{*}$ \\
\hline & & & & & $(3.001)$ & (3.393) & $(2.627)$ \\
\hline$R^{2}\left(\delta_{0}^{\ulcorner}\right)$ & 0.873 & 0.269 & 0.460 & 0.448 & 0.395 & 0.497 & 0.560 \\
\hline \multirow[t]{2}{*}{ Observations } & 7 & 37 & 37 & 37 & 37 & 37 & 37 \\
\hline & \multicolumn{7}{|c|}{$\lambda_{i}-\delta_{i}$ (log-risk-ratio of exiting to entering unemployment) } \\
\hline Numeracy (std) & -0.273 & 0.302 & $0.660^{* *}$ & $0.673^{*}$ & 0.217 & $0.644^{* *}$ & 0.555 \\
\hline & $(0.319)$ & $(0.255)$ & $(0.322)$ & $(0.355)$ & $(0.246)$ & $(0.327)$ & $(0.365)$ \\
\hline × Logarithmized GDP per capita (PPP, demeaned) & - & - & $1.249^{* * *}$ & - & - & 0.226 & -0.757 \\
\hline & & & $(0.367)$ & & & $(0.600)$ & $(0.666)$ \\
\hline$\times$ ICT in the workplace $(\mathrm{std})$ & - & - & - & $2.379^{* * *}$ & - & 1.674 & $3.090^{* * *}$ \\
\hline & & & & $(0.796)$ & & $(1.123)$ & $(1.184)$ \\
\hline × Employment in agriculture (share, demeaned) & - & - & - & - & $-14.394^{* * *}$ & -8.651 & $-11.087^{* *}$ \\
\hline & & & & & $(4.283)$ & $(5.445)$ & $(4.716)$ \\
\hline Logarithmized GDP per capita (PPP, demeaned) & - & - & $0.487^{*}$ & - & - & 0.106 & -0.249 \\
\hline & & & $(0.291)$ & & & $(0.383)$ & $(0.399)$ \\
\hline ICT in the workplace (std) & - & - & - & 0.572 & - & -0.088 & 0.194 \\
\hline & & & & $(0.386)$ & & $(0.509)$ & $(0.539)$ \\
\hline
\end{tabular}


Table 2 (continued)

\begin{tabular}{|c|c|c|c|c|c|c|c|}
\hline & \multicolumn{6}{|c|}{ Women and men } & \multirow{2}{*}{$\begin{array}{l}\text { Men } \\
\text { (7) }\end{array}$} \\
\hline & (1) & $(2)$ & (3) & (4) & (5) & (6) & \\
\hline Employment in agriculture (share, demeaned) & - & - & - & - & $\begin{array}{l}-16.243^{* * *} \\
(4.079)\end{array}$ & $\begin{array}{l}-13.334^{* * *} \\
(4.669)\end{array}$ & $\begin{array}{l}-10.965^{* * *} \\
(3.579)\end{array}$ \\
\hline$R^{2}\left(\lambda_{0}^{C}-\delta_{0}^{C}\right)$ & 0.299 & 0.148 & 0.362 & 0.374 & 0.422 & 0.507 & 0.444 \\
\hline Observations & 7 & 37 & 37 & 37 & 37 & 37 & 37 \\
\hline
\end{tabular}

Sample restricted to survey participants ages 25-54. Specification (1) for Indonesia, Ecuador, Peru, Mexico, Kazakhstan, Chile and Turkey. Fixed effects by round of data collection not displayed. Sampling weights employed in all calculations. Standard errors in parentheses. Statistical significance at the 10,5 , and $1 \%$ level denoted by

$*^{* * *}$, and ${ }^{* * *}$, respectively. Author's calculations based on the Survey of Adult Skills (PIAAC) and the Penn World Table 9.1 (Feenstra et al. 2015)

remain a key determinant of the international differences in the risk ratio of exiting to entering unemployment. ${ }^{12}$

Specification (1) in Table 2 effectively replicates the bivariate scatter plot in Fig. 2 for the seven skill-scarce countries, additionally controlling for fixed effects by round of data collection. The regression does not suggest a positive relation between numeracy skills and the risk ratio of exiting to entering unemployment. Indeed, the point estimate is negative yet statistically insignificant at conventional levels. In specification (2), I reestimate the relation on the full sample of 37 countries. The relation between skills and the risk ratio remains statistically insignificant at conventional levels. All in all, the documented positive relation between skills and employment among the skill-abundant countries does not seem to extend to the seven skill-scarce countries in the sample.

Why is the positive relation between skills and employment limited to the skill-abundant countries? A potential explanation is the distance to the technology frontier. Specifically, the hypothesis is that the skill-abundant countries are all at the same skillintensive technological frontier, whereas the skillscarce countries have not yet caught up, employing technologies that are less skill-intensive. Indeed, Fig. 2 illustrates that the seven skill-scarce countries are among the countries with the lowest GDP per capita and the lowest average use of ICT in the workplace. In order to explore the hypothesis further, I add interaction terms between measures of a country's skills and economic development to the set of controls. Specifically, specifications (3)-(5) in Table 2 additionally include the interaction term of the average numeracy score with GDP per capita as a measure of productive capacity, with the average use of ICT in the workplace as a measure of the prevalence of new technologies,

\footnotetext{
${ }^{12}$ In the regression of the numeracy score of the adult population on all other covariates, the numeracy score of teenagers (the PISA math score) has a F-statistic of 19.7 (3.5).
}

and with the employment share of the agricultural sector as a measure of structural change, respectively. In line with the stated hypothesis, the effect of numeracy skills on employment is positively associated with GDP, ICT and nonfarm employment.

The more complete specification (6) in Table 2 includes the interaction terms of the average numeracy score with all three measures of economic development. Neither GDP, ICT nor nonfarm employment has a statistically significant impact on the employment effect of skills conditional on the other factors. All in all, I cannot readily differentiate between the three factors in the present setup. Indeed, (logarithmized) GDP per capita, ICT use in the workplace and relative nonfarm employment have high pairwise correlations of $0.6-0.8$ in the sample. However, specification (7) on the sample of male survey participants favors the more direct measures of technology; in particular, ICT use in the workplace. I note that the seven skill-scarce countries in the sample, i.e., Indonesia, Ecuador, Peru, Mexico, Kazakhstan, Chile and Turkey, differ along various dimensions, e.g., informal economy (see, e.g., Medina and Schneider 2018), from the other 30 skill-abundant countries in the sample. However, the sample is not sufficiently large for a comprehensive study.

\section{Individual-level evidence}

In order to obtain estimates of the employment effects of skills at the individual level, I maximize the likelihood function in Eq. (3) on the pooled international sample, directly taking into account the contribution of individual characteristics, $x_{i}$. I assume the effects of the various covariates on the exit rate from and the entry rate into unemployment to be log-linear. Table 3 displays the individual-level estimates. I allow for country-level fixed effects in order to control for differences in labor markets across countries. (Potential) experience is equal to age minus six minus years of schooling, i.e., the typical number of years 
Table 3 Individual-level maximum-likelihood estimates of the effects of the displayed variables on the risks of exiting unemployment and of entering unemployment

\begin{tabular}{|c|c|c|c|c|c|c|c|}
\hline & (1) & (2) & (3) & (4) & (5) & (6) & (7) \\
\hline & \multicolumn{7}{|c|}{$\lambda_{i}$ (log-risk of exiting unemployment) } \\
\hline \multirow[t]{2}{*}{ Numeracy (std) } & $0.166^{* * *}$ & $0.174^{* * *}$ & 0.084 & $0.162^{* * *}$ & $0.165^{* * *}$ & $0.164^{* * *}$ & $0.163^{* * *}$ \\
\hline & $(0.029)$ & $(0.032)$ & $(0.073)$ & $(0.030)$ & $(0.030)$ & $(0.029)$ & $(0.031)$ \\
\hline \multirow[t]{2}{*}{ × Logarithmized GDP per capita (PPP, demeaned) } & - & - & - & 0.043 & - & - & 0.028 \\
\hline & & & & $(0.061)$ & & & $(0.096)$ \\
\hline \multirow[t]{2}{*}{$\times I C T$ in the workplace $(s t d)$} & - & - & - & - & 0.061 & - & 0.032 \\
\hline & & & & & $(0.120)$ & & $(0.192)$ \\
\hline \multirow[t]{2}{*}{ × Employment in agriculture (share, demeaned) } & - & - & - & - & - & -0.352 & 0.054 \\
\hline & & & & & & $(0.838)$ & $(0.970)$ \\
\hline \multirow[t]{2}{*}{ Experience (decades) } & -0.002 & -0.010 & 0.144 & -0.003 & -0.004 & -0.002 & -0.004 \\
\hline & $(0.082)$ & $(0.075)$ & $(0.361)$ & $(0.082)$ & $(0.082)$ & $(0.082)$ & $(0.082)$ \\
\hline \multirow[t]{2}{*}{ Experience $^{2}$ (decades) } & -0.017 & -0.013 & -0.068 & -0.016 & -0.016 & -0.017 & -0.016 \\
\hline & $(0.020)$ & $(0.018)$ & $(0.103)$ & $(0.020)$ & $(0.020)$ & $(0.020)$ & $(0.020)$ \\
\hline \multirow[t]{2}{*}{ Female } & $-0.276^{* * *}$ & $-0.232^{* * *}$ & $-0.662^{* * *}$ & $-0.276^{* * *}$ & $-0.276^{* * *}$ & $-0.276^{* * *}$ & $-0.276^{* * *}$ \\
\hline & $(0.043)$ & $(0.041)$ & $(0.116)$ & $(0.043)$ & $(0.043)$ & $(0.043)$ & $(0.043)$ \\
\hline Log-likelihood & $-30,221$ & $-26,470$ & $-3,691$ & $-30,203$ & $-30,201$ & $-30,205$ & $-30,198$ \\
\hline Countries & 37 & 30 & 7 & 37 & 37 & 37 & 37 \\
\hline \multirow[t]{2}{*}{ Observations } & 115,998 & 97,414 & 18,584 & 115,998 & 115,998 & 115,998 & 115,998 \\
\hline & \multicolumn{7}{|c|}{$\delta_{i}$ (log-risk of entering unemployment) } \\
\hline \multirow[t]{2}{*}{ Numeracy (std) } & $-0.335^{* * *}$ & $-0.356^{* * *}$ & -0.171 & $-0.324^{* * *}$ & $-0.338^{* * *}$ & $-0.331^{* * *}$ & $-0.332^{* * *}$ \\
\hline & $(0.042)$ & $(0.044)$ & $(0.119)$ & $(0.040)$ & $(0.038)$ & $(0.038)$ & $(0.039)$ \\
\hline \multirow[t]{2}{*}{ × Logarithmized GDP per capita (PPP, demeaned) } & - & - & - & $-0.170^{*}$ & - & - & -0.042 \\
\hline & & & & $(0.087)$ & & & $(0.142)$ \\
\hline \multirow[t]{2}{*}{$\times I C T$ in the workplace $(\mathrm{std})$} & - & - & - & - & -0.271 & - & -0.145 \\
\hline & & & & & $(0.171)$ & & $(0.267)$ \\
\hline \multirow[t]{2}{*}{$\times$ Employment in agriculture (share, demeaned) } & - & - & - & - & - & $2.230^{*}$ & 1.029 \\
\hline & & & & & & $(1.153)$ & $(1.392)$ \\
\hline \multirow[t]{2}{*}{ Experience (decades) } & $-0.453^{* * *}$ & $-0.399^{* * *}$ & $-0.719^{*}$ & $-0.449^{* * *}$ & $-0.450^{* * *}$ & $-0.449^{* * *}$ & $-0.449^{* * *}$ \\
\hline & $(0.101)$ & $(0.094)$ & $(0.424)$ & $(0.101)$ & $(0.101)$ & $(0.101)$ & $(0.101)$ \\
\hline \multirow[t]{2}{*}{ Experience $^{2}$ (decades) } & $0.059^{* *}$ & $0.051^{* *}$ & 0.082 & $0.058^{* *}$ & $0.058^{* *}$ & $0.058^{* *}$ & $0.058^{* *}$ \\
\hline & $(0.025)$ & $(0.024)$ & $(0.112)$ & $(0.025)$ & $(0.025)$ & $(0.025)$ & $(0.025)$ \\
\hline \multirow[t]{2}{*}{ Female } & $-0.135^{* *}$ & $-0.137^{*}$ & -0.117 & $-0.136^{* *}$ & $-0.135^{* *}$ & $-0.135^{* *}$ & $-0.136^{* *}$ \\
\hline & $(0.068)$ & $(0.072)$ & $(0.195)$ & $(0.068)$ & $(0.068)$ & $(0.068)$ & $(0.068)$ \\
\hline Log-likelihood & $-30,221$ & $-26,470$ & $-3,691$ & $-30,203$ & $-30,201$ & $-30,205$ & $-30,198$ \\
\hline Countries & 37 & 30 & 7 & 37 & 37 & 37 & 37 \\
\hline \multirow[t]{2}{*}{ Observations } & 115,998 & 97,414 & 18,584 & 115,998 & 115,998 & 115,998 & 115,998 \\
\hline & \multicolumn{7}{|c|}{$\lambda_{i}-\delta_{i}$ (log-risk-ratio of exiting to entering unemployment) } \\
\hline \multirow[t]{2}{*}{ Numeracy (std) } & $0.501^{* * *}$ & $0.530^{* * *}$ & $0.255^{* * *}$ & $0.486^{* * *}$ & $0.503^{* * *}$ & $0.495^{* * *}$ & $0.495^{* * *}$ \\
\hline & $(0.039)$ & $(0.040)$ & $(0.062)$ & $(0.036)$ & $(0.034)$ & $(0.034)$ & $(0.034)$ \\
\hline \multirow[t]{2}{*}{ × Logarithmized GDP per capita (PPP, demeaned) } & - & - & - & $0.213^{* *}$ & - & - & 0.070 \\
\hline & & & & $(0.086)$ & & & $(0.156)$ \\
\hline$\times I C T$ in the workplace $(\mathrm{std})$ & - & - & - & - & $0.332^{* *}$ & - & 0.177 \\
\hline & & & & & $(0.149)$ & & $(0.189)$ \\
\hline x Employment in agriculture (share, demeaned) & - & - & - & - & - & $-2.582^{* *}$ & -0.975 \\
\hline & & & & & & $(1.085)$ & $(1.620)$ \\
\hline Experience (decades) & $0.451^{* * *}$ & $0.389^{* * *}$ & $0.863^{* * *}$ & $0.446^{* * *}$ & $0.447^{* * *}$ & $0.447^{* * *}$ & $0.445^{* * *}$ \\
\hline & $(0.069)$ & $(0.071)$ & $(0.188)$ & $(0.069)$ & $(0.069)$ & $(0.070)$ & $(0.069)$ \\
\hline Experience $^{2}$ (decades) & $-0.075^{* * *}$ & $-0.063^{* * *}$ & $-0.150^{* * *}$ & $-0.074^{* * *}$ & $-0.074^{* * *}$ & $-0.074^{* * *}$ & $-0.074^{* * *}$ \\
\hline
\end{tabular}


Table 3 (continued)

\begin{tabular}{llllllll}
\hline & $(1)$ & $(2)$ & $(3)$ & $(4)$ & $(5)$ & $(6)$ & $(7)$ \\
\hline Female & $(0.016)$ & $(0.018)$ & $(0.040)$ & $(0.016)$ & $(0.016)$ & $(0.016)$ & $(0.016)$ \\
& $-0.141^{* *}$ & -0.094 & $-0.546^{* * *}$ & $-0.140^{* *}$ & $-0.140^{* *}$ & $-0.140^{* *}$ & $-0.140^{* *}$ \\
Log-likelihood & $(0.065)$ & $(0.068)$ & $(0.173)$ & $(0.065)$ & $(0.065)$ & $(0.065)$ & $(0.065)$ \\
Countries & $-30,221$ & $-26,470$ & $-3,691$ & $-30,203$ & $-30,201$ & $-30,205$ & $-30,198$ \\
Observations & 37 & 30 & 7 & 37 & 37 & 37 & 37 \\
\hline
\end{tabular}

Sample restricted to survey participants ages 25-54. Specification (2) and specification (3) exclude survey participants from Indonesia, Ecuador, Peru, Mexico, Kazakhstan, Chile and Turkey, and from all other countries, respectively. Fixed effects by country not displayed. Sampling weights employed in all calculations, giving the same weight to each country. Robust standard errors in parentheses, adjusted for clustering at the country level. Statistical significance at the 10,5 , and $1 \%$ level denoted by ${ }^{* * *}{ }^{*}$ and $^{* * *}$, respectively. Author's calculations based on the Survey of Adult Skills (PIAAC) and the Penn World Table 9.1 (Feenstra et al. 2015)

that are associated with the person's highest level of education. ${ }^{13}$

Specification (1) in Table 3 displays the individual-level estimates for the pooled international sample including all 37 countries. Numeracy skills are estimated to increase the exit rate from unemployment and to lower the entry rate into unemployment-well in line with the countrylevel estimates. Specifically, a one-standard-deviation increase in numeracy skills is associated with an increase in the exit rate from unemployment and with a decrease in the entry rate into unemployment by a factor of 1.2 $(\exp (0.165))$ and by a factor of $0.7(\exp (-0.335))$, respectively. Hence, the risk ratio of exiting to entering unemployment rises by a factor of $1.7(\exp (0.165+0.335))$.

In specification (2) and in specification (3) of Table 3, I estimate the transition parameters for the 30 skill-abundant countries and for the seven skill-scarce countries separately. Numeracy skills are estimated to have a substantially smaller impact on the risk ratio of exiting to entering unemployment in the skill-scarce countries than in the skill-abundant countries. In light of the present paper's scope, it is tempting to conclude that skills are less important for a successful participation in the labor market in the seven skill-scarce countries. However, there are other competing explanations, between which I cannot readily differentiate. My definition of unemployment may poorly reflect the situation in the skill-scarce countries. Furthermore, the most destituted individuals may face subsistence and borrowing constraints that make longer unemployment spells unfeasible even in the case of expected positive returns. Skills may be associated

\footnotetext{
${ }^{13}$ This variable is not available in the German public-use file. I compute the years of schooling in the German sample based on the International Standard Classification of Education (ISCED) and the mapping of the UNESCO Institute for Statistics (UIS); accessed at http://uis.unesco.org/en/isced-mappings/
} on December 20, 2020. with disposable resources as a prerequisite for the trade-off between shorter search spells and better jobs. Notably, Bick et al. (2018) document that average hours worked per adult are substantially higher along the extensive and intensive margin in low-income countries than in high-income countries.

In order to further explore the international differences in the employment effects of skills, I extend the set of controls to include interaction terms between the numeracy score and measures of economic development in specifications (4)-(7) of Table 3. In line with the country-level estimates, I document that the effect of numeracy skills on the risk ratio of exiting to entering unemployment is positively associated with GDP per capita, with average ICT use in the workplace and with nonfarm employment across countries. However, I cannot readily differentiate between the three factors in the present setup.

\section{Conclusion}

I construct aggregate data from the PIAAC survey data in order to study the aggregate-level effects of skills, complementing the large and influential body of literature that studies how skills contributes to an individual's success in life. In general, the social returns can be quite different from the private returns to skills. My analysis is unique in the sense that it exploits highly internationally comparable data from a large set of countries in order to explore the effects of directly assessed skills on the ins and outs of unemployment.

Across the 30 advanced and skill-abundant countries in the sample, I document that skills have a pronounced unconditional correlation with the logrisk-ratio of exiting to entering unemployment irrespective of the specific domain: 0.65 for literacy and 0.68 for numeracy. The average numeracy score ranges from 255 in Spain to 298 in Japan. Evaluated 
at this range, the estimates suggest an increase in the ratio of employed to unemployed workers by a factor of 4.3 , corresponding to a fall in the unemployment rate from 18.2 to $5.0 \%$ in the case of Spain.

The relation between skills and unemployment flows is remarkably robust across the 30 advanced countries in the sample. Instrumental-variable estimates reject the hypothesis that the relation is exclusively driven by reverse causality, i.e., labor-market conditions affecting the skills of the labor force. Strictly speaking, I cannot firmly establish causality. Nevertheless, the key determinants of the differences across advanced countries in unemployment flows are skills or at least factors that are closely related to skills. I do not find evidence that this relation between skills and unemployment flows extends to less advanced economies.

\section{Appendix: Data and auxiliary results}

Further data details and summary statistics are in Appendix 1 and the auxiliary results are in Appendix 2.

\section{Appendix 1: Data}

Survey participants are classified as employed if they answer either of the two questions in the affirmative: "In the last week, did you do any PAID work for at least one hour, either as an employee or as selfemployed?" (C_Q01a) or "Last week, were you away from a job or business that you plan to return to?" (C_Q01b)

In order to identify unemployed individuals, I rely on three survey questions: (i) "In the 4 weeks ending last Sunday, were you looking for paid work at any time?" (C_Q02a), (ii) "In the four weeks ending last Sunday, did you do any of these things...": "get in contact with a public employment office to find work?" (C_Q04a) or "get in contact with a private agency (temporary work agency, firm specialising in recruitment, etc.) to find work?" (C_Q04b) or "apply to employers directly?" (C_Q04c) or "ask among friends, relatives, unions, etc. to find work?" (C_Q04d) or "place or answer job advertisements?" (C_Q04e) or "take a recruitment test or examination or undergo an interview?" (C_Q04g) or "look for land, premises or equipment for work?" (C_Q04h) or "apply for permits, licences or financial resources for work?” (C_Q04i), and (iii) "If a job had been available in the week ending last Sunday, would you have been able to start within 2 weeks?" (C_Q05). I classify survey participants as unemployed if they answer the first and the third question in the affirmative and indicate having been engaged in at least one of the eight activities stated in the second question.

The distinction of short-term and long-term unemployed survey participants is based on the following two questions: "Have your ever had paid work? Please include self-employment." (C_Q08a) and "During the last 12 months, that is since MonthYear, did you have any paid work? Please include self-employment." (C_Q08b). I classify respondents as long-term unemployed if they indicate never having had paid work or at least not having had paid work during the preceding twelve months. If the latter question is answered in the affirmative, I categorize the person as shortterm unemployed.

I note that most questions on which this classification of survey participants is based are used to determine the question routing. For instance, the interviewers obtain the following instruction for question C_Q01a: “The question is crucial for the routing. Don't knows and refusals are to be minimised. Please probe for an answer."

Table 4 displays summary statistics and the maximum-likelihood estimates of the unconditional transition rates for the pooled international sample and by country. I also make use of the publicly available annual time series on the number of employed, unemployed and long-term unemployed workers from the OECD database and from the ILO database. Figure 3 juxtaposes labor statistics based on my PIAAC sample with the respective statistics from the OECD and ILO databases. The ratio of employed to unemployed workers is highly correlated across the different data sources. However, the discrepancies are particularly large for Belgium and for Japan. I note that the PIAAC data is for the Flemish region exclusively, whereas the OECD data and ILO data are for the entire country. The OECD, ILO and PIAAC ratio of employed to unemployed workers in Japan are 22, 22 and 44, respectively. Notably, the PIAAC statistics based on observed behavior substantially differ from those based on the self-reported classification in the case of Japan. Specifically, the ratio of employed to unemployed workers based on the self-assessed classification in the PIAAC is 23, i.e., it is approximately one-half of the ratio that is based on observed behavior. The ratio of short-term to long-term unemployed workers is less highly correlated across the different data sources. According to the OECD database and the ILO database, the ratio of short-term to long-term 


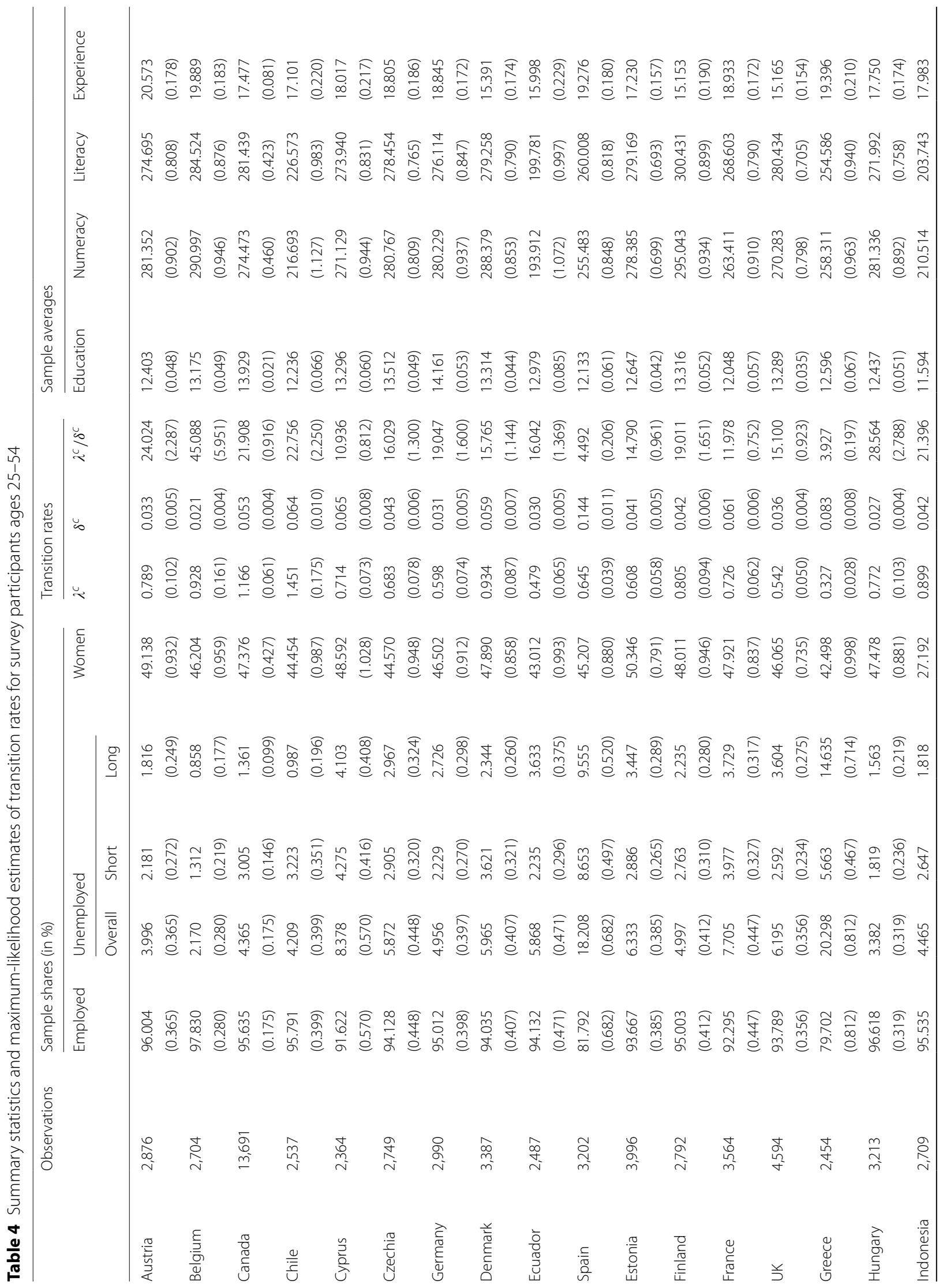




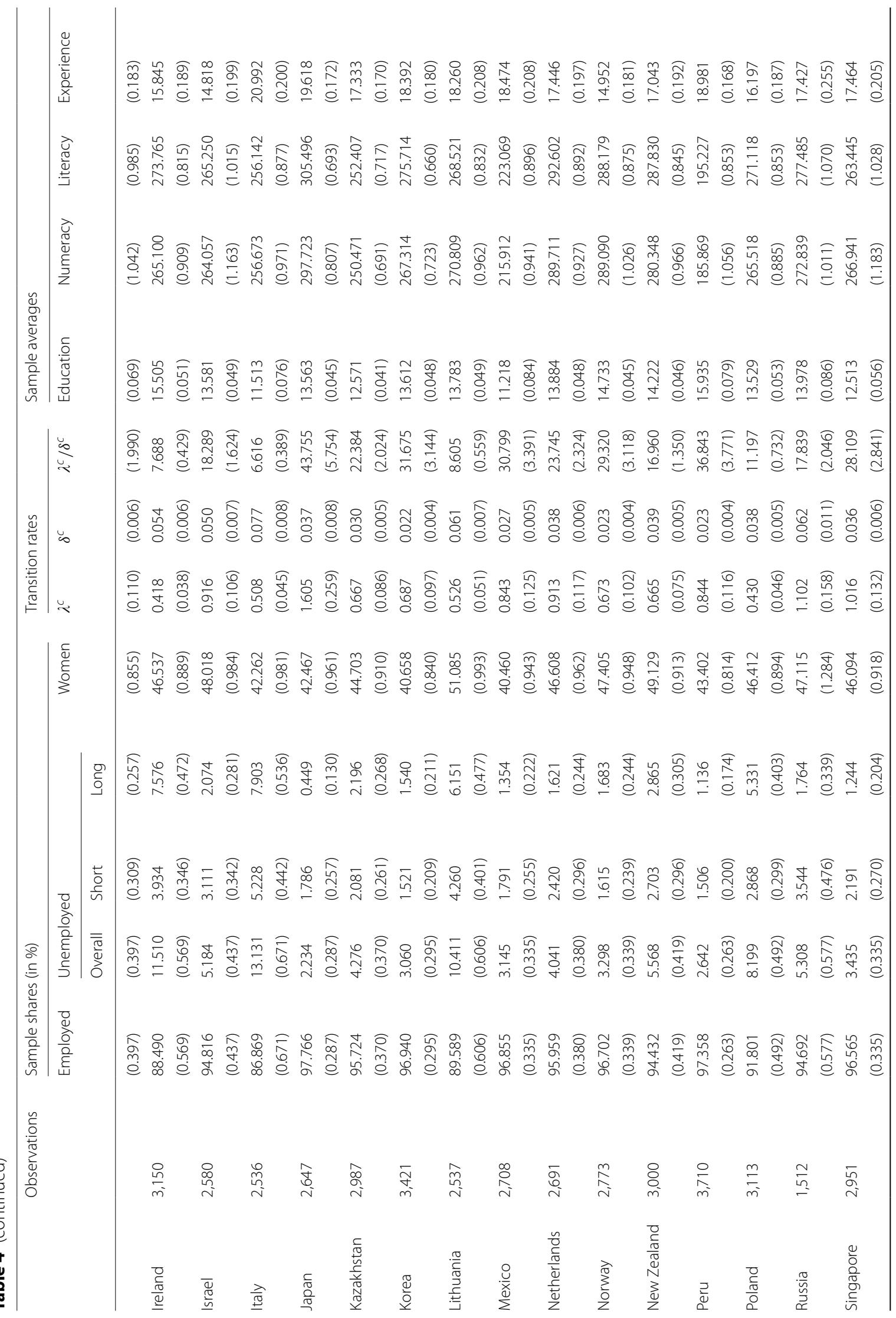




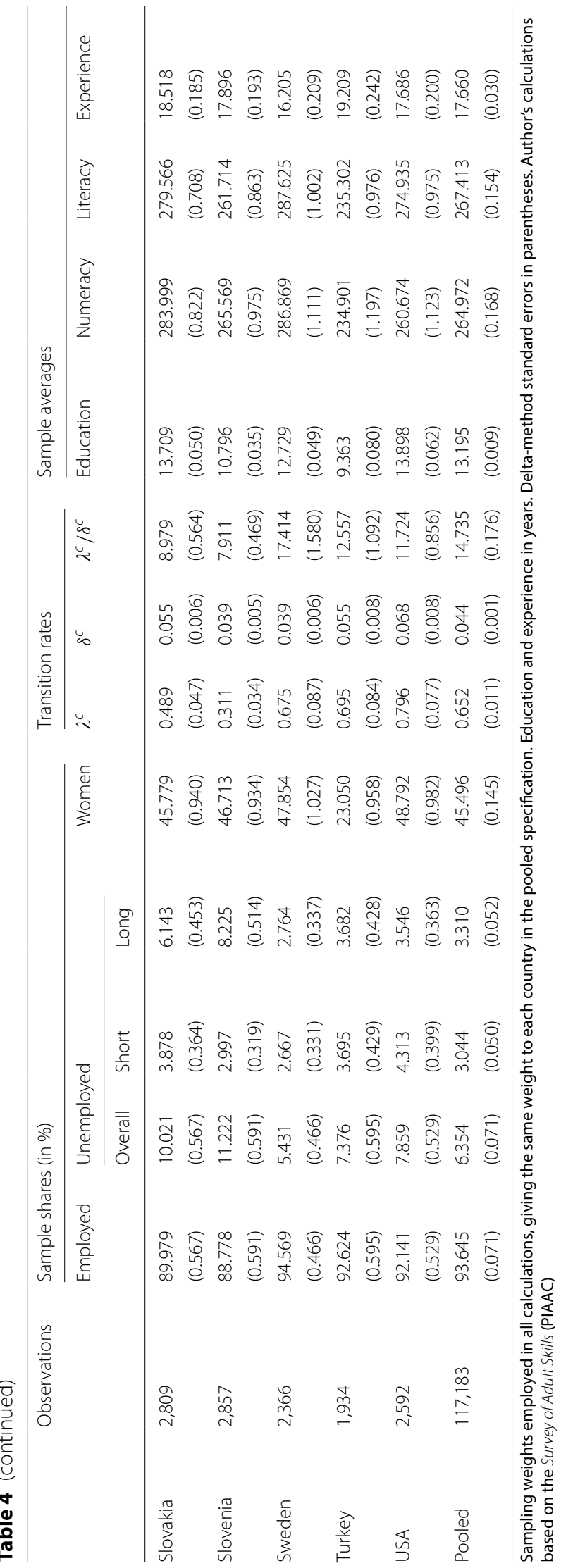



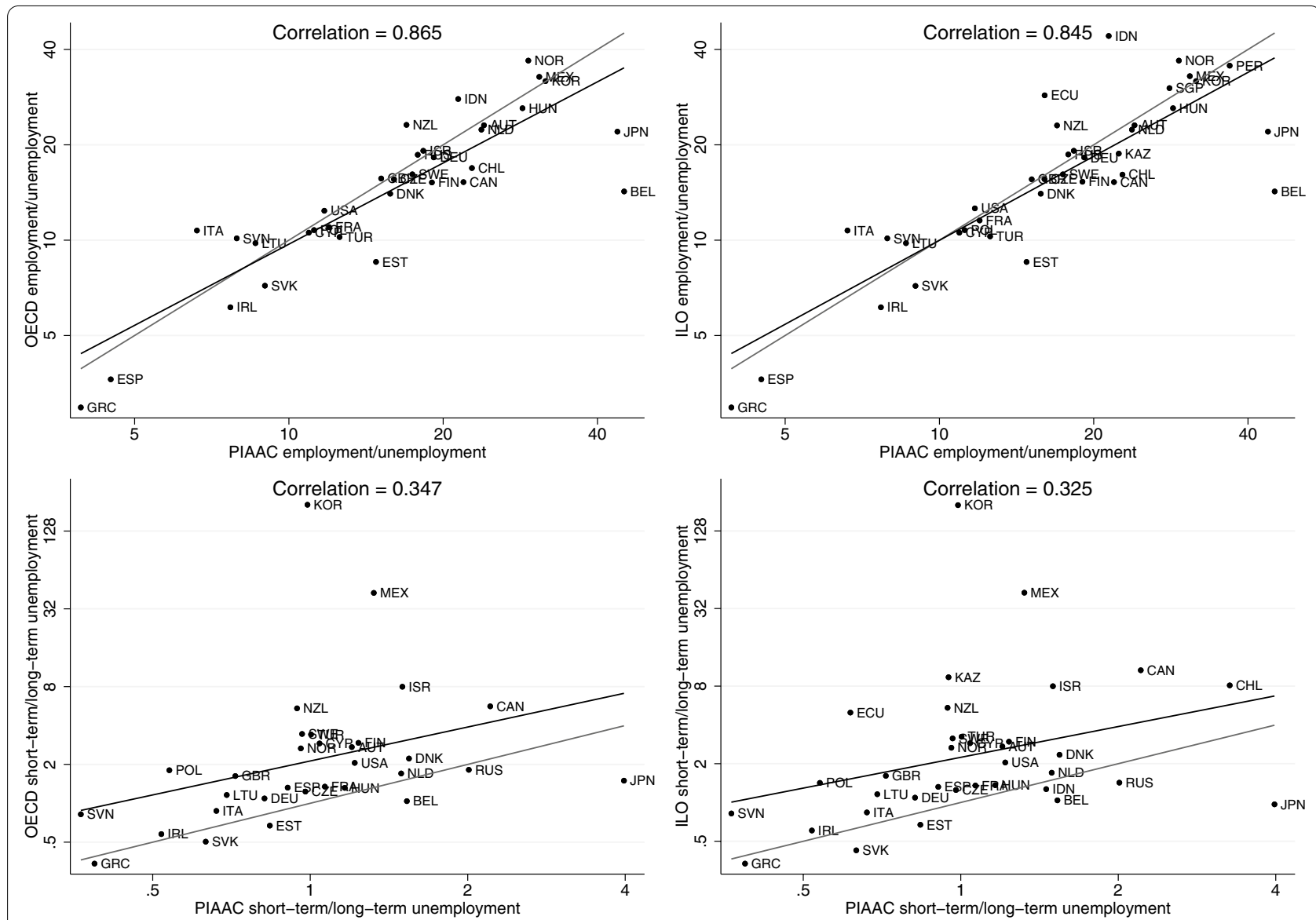

Fig. 3 Comparison of unemployment statistics based on the PIAAC data with unemployment statistics from the OECD and ILO databases. Ordinary least-squares lines (black) and 45-degree lines (gray) depicted. Sample restricted to survey participants ages 25-54. Sampling weights employed in all calculations. Author's calculations based on the Survey of Adult Skills (PIAAC), OECD statistics (https://stats.oecd.org/) and ILO statistics (https:// ilostat.ilo.org/data/)

unemployed workers is extremely high in some countries, exceeding 40 in Mexico and 200 in Korea.

\section{Appendix 2: Auxiliary results}

In a first sensitivity analysis, I reestimate specification (5) of Table 1 dropping one country at a time from the sample. Figure 4 displays the estimated effects of numeracy skills on the transition rates once the respective country is excluded from the sample. The effect of skills on the risk ratio of exiting to entering unemployment remains statistically significant at the one-percent level in all estimations, indicating that the cross-country pattern is not driven by individual countries. Furthermore, I reestimate specification (5) of Table 1 for four age groups, i.e., 25-34, 35-44, 45-54 and 55-64, and for three education groups, i.e., less than high school (low), high school (medium) and more than high school (high). Table 5 displays the estimates for each subgroup separately. The effect of skills on the risk ratio of exiting to entering unemployment is statistically significant at the five-percent level in all subgroups.

In the baseline specification, I distinguish workers who have been unemployed for less than a year and workers who have been unemployed for at least a year in order to identify the exit rate from unemployment. However, most countries report the unemployment duration in months in their public-use files. For those countries, I additionally exploit the variation in unemployment spells of less than a year in order to obtain an alternative estimate of the exit rate. Under the constant inflow assumption, the probability of observing a worker with an unemployment duration of $n$ months is $\exp \left(-\mu \frac{n}{12}\right)-\exp \left(-\mu \frac{n+1}{12}\right)$, where $\mu$ denotes the 


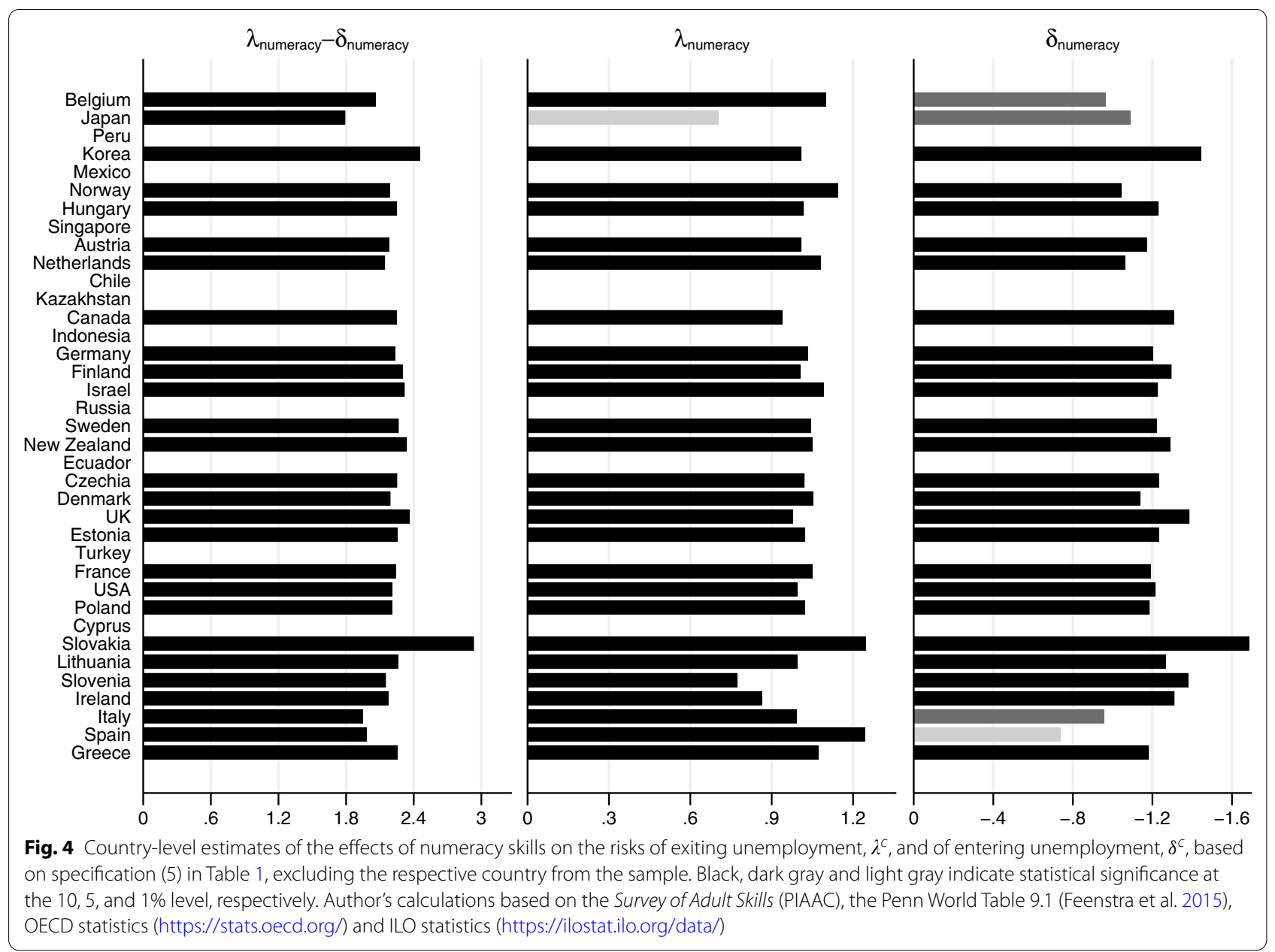

alternative exit rate. The alternative entry rate into unemployment, denoted by $\rho$, is determined by the condition that unemployment is at its steady state, i.e., $\rho /(\mu+\rho)$. Figure 5 displays the country pairs of the baseline and alternative transition rates. All alternative transition rates are above the 45-degree line, i.e., additionally exploiting the variation in shorter unemployment spells leads to higher estimates of the exit rate from unemployment and, hence, to higher estimates of the entry rate into unemployment. I also reestimate specification (5) of Table 1 with the alternative transition rates. The first specification in Table 6 shows the estimates. The main qualitative implications are unaltered.

In order to derive the likelihood function in Eq. (3), I impose that unemployment is at its steady-state level. This assumption is necessary since the PIAAC data is typically based on a single cross-sectional survey per country with only limited longitudinal information. However, with the OECD times series and the ILO time series, I can relax this assumption. For an arbitrary probability of being unemployed in the year $t$, the probability of being unemployed in the year $t+1$ is

$$
\begin{aligned}
P\left(s_{t+1}=u\right)= & \left(1-\mathrm{e}^{-(\lambda+\delta)}\right) \frac{\delta}{\lambda+\delta} \\
& +\mathrm{e}^{-(\lambda+\delta)} \mathrm{P}\left(\mathrm{s}_{\mathrm{t}}=\mathrm{u}\right) .
\end{aligned}
$$

Additionally exploiting the relation in Eq. (1) or in Eq. (2), data on the number of employed, unemployed and long-term unemployed workers in the current and in the previous year is then sufficient to identify the exit rate from unemployment and the entry rate into unemployment. Shimer (2012) provides a more detailed exposition. I reestimate specification (5) of Table 1 with the OECD and ILO transition rates as implied by Eqs. (1) and (5). The second and third specification in Table 6 display the 
Table 5 Country-level estimates of the effects of the displayed variables on the risks of exiting unemployment and of entering unemployment in a seemingly unrelated regressions setup à la Zellner (1962)

\begin{tabular}{|c|c|c|c|c|c|c|c|}
\hline & \multicolumn{4}{|l|}{ Age } & \multicolumn{3}{|l|}{ Education } \\
\hline & $25-34$ & $35-44$ & $45-54$ & $55-65$ & Low & Medium & High \\
\hline & \multicolumn{7}{|c|}{$\lambda_{i}$ (log-risk of exiting unemployment) } \\
\hline \multirow[t]{2}{*}{ Numeracy (std) } & $0.749 * *$ & $1.485^{* * *}$ & $0.706^{* *}$ & $1.582^{* * *}$ & 0.614 & $1.074^{* * *}$ & $1.109 * * *$ \\
\hline & $(0.340)$ & $(0.395)$ & $(0.280)$ & $(0.605)$ & $(0.447)$ & $(0.394)$ & $(0.418)$ \\
\hline \multirow[t]{2}{*}{ Logarithmized GDP per capita (PPP) } & $0.700 * *$ & 0.590 & 0.541 & $1.394^{*}$ & -0.096 & $1.077^{* * *}$ & $0.618^{*}$ \\
\hline & $(0.329)$ & $(0.442)$ & $(0.360)$ & $(0.779)$ & $(0.454)$ & $(0.350)$ & $(0.358)$ \\
\hline \multirow[t]{2}{*}{ Employment in public sector (share) } & 0.114 & $-3.704^{* * *}$ & $-1.731 *$ & 0.168 & $-3.579^{* *}$ & 0.165 & -0.341 \\
\hline & $(1.274)$ & $(1.248)$ & $(1.007)$ & $(1.737)$ & $(1.461)$ & $(1.798)$ & $(1.035)$ \\
\hline \multirow[t]{2}{*}{ ICT in the workplace (std) } & -0.270 & -0.717 & 0.059 & -0.552 & 0.787 & -0.386 & -0.311 \\
\hline & $(0.406)$ & $(0.561)$ & $(0.434)$ & $(0.897)$ & $(0.819)$ & $(0.382)$ & $(0.404)$ \\
\hline \multirow[t]{2}{*}{ Minimum relative to median wage } & -0.266 & 0.392 & 1.126 & 3.060 & 2.132 & 0.094 & 0.267 \\
\hline & $(1.068)$ & $(1.248)$ & $(1.012)$ & $(2.154)$ & $(1.547)$ & $(1.047)$ & $(1.132)$ \\
\hline \multirow[t]{2}{*}{ Trade union density } & -0.356 & 0.678 & -0.781 & 0.440 & 0.305 & -0.462 & 0.069 \\
\hline & $(0.478)$ & $(0.571)$ & $(0.478)$ & $(0.944)$ & $(0.677)$ & $(0.611)$ & $(0.510)$ \\
\hline \multirow[t]{2}{*}{ Unemployment benefits (level) } & 0.698 & 0.383 & $1.693^{* * *}$ & -0.228 & 0.634 & $1.106^{*}$ & -0.341 \\
\hline & $(0.623)$ & $(0.746)$ & $(0.613)$ & $(1.354)$ & $(0.794)$ & $(0.649)$ & $(0.727)$ \\
\hline \multirow[t]{2}{*}{ Unemployment benefits (degression) } & 0.365 & 0.254 & 0.159 & 1.154 & 0.566 & 0.247 & 0.257 \\
\hline & $(0.420)$ & $(0.532)$ & $(0.414)$ & $(0.870)$ & $(0.601)$ & $(0.456)$ & $(0.484)$ \\
\hline \multirow[t]{2}{*}{ Employment protection (regular) } & $-0.212^{*}$ & -0.227 & $-0.262^{* *}$ & $-0.533^{* *}$ & -0.066 & $-0.293^{* *}$ & -0.007 \\
\hline & $(0.128)$ & $(0.146)$ & $(0.116)$ & $(0.249)$ & $(0.168)$ & $(0.134)$ & $(0.138)$ \\
\hline \multirow[t]{2}{*}{ Employment protection (temporary) } & -0.014 & -0.039 & 0.030 & 0.110 & 0.019 & -0.013 & -0.074 \\
\hline & $(0.078)$ & $(0.095)$ & $(0.079)$ & $(0.182)$ & $(0.103)$ & $(0.082)$ & $(0.086)$ \\
\hline$R^{2}\left(\lambda_{0}^{c}\right)$ & 0.538 & 0.665 & 0.655 & 0.584 & 0.459 & 0.683 & 0.528 \\
\hline \multirow[t]{2}{*}{ Observations } & 27 & 27 & 27 & 27 & 26 & 26 & 26 \\
\hline & \multicolumn{7}{|c|}{$\delta_{i}($ log-risk of entering unemployment) } \\
\hline \multirow[t]{2}{*}{ Numeracy (std) } & $-1.918^{* * *}$ & -0.243 & $-1.220^{* * *}$ & -0.577 & -0.480 & -0.606 & $-1.788^{* * *}$ \\
\hline & $(0.485)$ & $(0.500)$ & $(0.428)$ & $(0.626)$ & $(0.479)$ & $(0.497)$ & $(0.514)$ \\
\hline \multirow[t]{2}{*}{ Logarithmized GDP per capita (PPP) } & -0.319 & 0.496 & -0.635 & -0.969 & $-1.341^{* * *}$ & -0.449 & -0.240 \\
\hline & $(0.468)$ & $(0.559)$ & $(0.551)$ & $(0.805)$ & $(0.486)$ & $(0.440)$ & $(0.441)$ \\
\hline \multirow[t]{2}{*}{ Employment in public sector (share) } & 0.039 & 0.037 & $5.115^{* * *}$ & $3.258^{*}$ & $6.973^{* * *}$ & $4.028^{*}$ & 0.318 \\
\hline & $(1.817)$ & $(1.581)$ & $(1.540)$ & $(1.796)$ & $(1.564)$ & $(2.265)$ & $(1.273)$ \\
\hline \multirow[t]{2}{*}{ ICT in the workplace (std) } & -0.148 & $-2.474^{* * *}$ & -0.141 & 0.084 & $2.212^{* *}$ & 0.296 & 0.157 \\
\hline & $(0.579)$ & $(0.711)$ & $(0.664)$ & $(0.927)$ & $(0.877)$ & $(0.481)$ & $(0.497)$ \\
\hline \multirow[t]{2}{*}{ Minimum relative to median wage } & -1.010 & -1.710 & $-4.373^{* * *}$ & -1.485 & $-2.793^{*}$ & -0.958 & -1.651 \\
\hline & $(1.522)$ & $(1.582)$ & $(1.548)$ & $(2.226)$ & $(1.656)$ & $(1.318)$ & $(1.392)$ \\
\hline \multirow[t]{2}{*}{ Trade union density } & 0.884 & 0.068 & $-2.446^{* * *}$ & -0.976 & $-2.195^{* * *}$ & -0.916 & -0.055 \\
\hline & $(0.681)$ & $(0.724)$ & $(0.731)$ & $(0.976)$ & $(0.725)$ & $(0.769)$ & $(0.627)$ \\
\hline Unemployment benefits (level) & 0.297 & $1.712^{*}$ & $2.578^{* * *}$ & -0.887 & 0.958 & 0.476 & -0.191 \\
\hline & $(0.888)$ & $(0.945)$ & $(0.938)$ & $(1.399)$ & $(0.850)$ & $(0.818)$ & $(0.894)$ \\
\hline Unemployment benefits (degression) & -0.193 & $-1.672^{* *}$ & -0.984 & -0.443 & $1.477^{* *}$ & -0.601 & -0.974 \\
\hline & $(0.599)$ & $(0.674)$ & $(0.632)$ & $(0.899)$ & $(0.644)$ & $(0.574)$ & $(0.596)$ \\
\hline Employment protection (regular) & 0.082 & -0.260 & -0.285 & -0.410 & $-0.714^{* * *}$ & $-0.389 * *$ & $0.330^{*}$ \\
\hline & $(0.183)$ & $(0.185)$ & $(0.178)$ & $(0.257)$ & $(0.180)$ & $(0.169)$ & $(0.169)$ \\
\hline Employment protection (temporary) & 0.014 & $-0.230^{*}$ & -0.062 & -0.132 & 0.180 & 0.017 & -0.130 \\
\hline & $(0.112)$ & $(0.121)$ & $(0.121)$ & $(0.188)$ & $(0.110)$ & $(0.103)$ & $(0.105)$ \\
\hline$R^{2}\left(\delta_{0}^{\complement}\right)$ & 0.590 & 0.476 & 0.636 & 0.474 & 0.646 & 0.483 & 0.530 \\
\hline Observations & 27 & 27 & 27 & 27 & 26 & 26 & 26 \\
\hline & $\lambda_{i}-\delta_{i}(\log$ & k-ratio of exiti & o entering $u$ & nployment) & & & \\
\hline
\end{tabular}


Table 5 (continued)

\begin{tabular}{|c|c|c|c|c|c|c|c|}
\hline & \multicolumn{4}{|l|}{ Age } & \multicolumn{3}{|l|}{ Education } \\
\hline & $25-34$ & $35-44$ & $45-54$ & $55-65$ & Low & Medium & High \\
\hline \multirow[t]{2}{*}{ Numeracy (std) } & $2.666^{* * *}$ & $1.728^{* * *}$ & $1.926^{* * *}$ & $2.159^{* * *}$ & $1.093^{* *}$ & $1.680^{* * *}$ & $2.897^{* * *}$ \\
\hline & $(0.424)$ & $(0.486)$ & $(0.442)$ & $(0.332)$ & $(0.501)$ & $(0.580)$ & $(0.464)$ \\
\hline \multirow[t]{2}{*}{ Logarithmized GDP per capita (PPP) } & $1.019^{* *}$ & 0.094 & $1.175^{* *}$ & $2.363^{* * *}$ & $1.245^{* *}$ & $1.526^{* * *}$ & $0.858^{* *}$ \\
\hline & $(0.409)$ & $(0.544)$ & $(0.569)$ & $(0.427)$ & $(0.508)$ & $(0.514)$ & $(0.398)$ \\
\hline \multirow[t]{2}{*}{ Employment in public sector (share) } & 0.075 & $-3.742^{* *}$ & $-6.846^{* * *}$ & $-3.090^{* * *}$ & $-10.553^{* * *}$ & -3.862 & -0.659 \\
\hline & $(1.587)$ & $(1.537)$ & $(1.593)$ & $(0.953)$ & $(1.636)$ & $(2.643)$ & $(1.149)$ \\
\hline \multirow[t]{2}{*}{ ICT in the workplace (std) } & -0.121 & $1.756^{* *}$ & 0.200 & -0.636 & -1.424 & -0.682 & -0.467 \\
\hline & $(0.506)$ & $(0.691)$ & $(0.687)$ & $(0.492)$ & $(0.917)$ & $(0.561)$ & $(0.448)$ \\
\hline \multirow[t]{2}{*}{ Minimum relative to median wage } & 0.744 & 2.101 & $5.500^{* * *}$ & $4.544^{* * *}$ & $4.925^{* * *}$ & 1.052 & 1.918 \\
\hline & $(1.330)$ & $(1.538)$ & $(1.600)$ & $(1.182)$ & $(1.732)$ & $(1.539)$ & $(1.256)$ \\
\hline \multirow[t]{2}{*}{ Trade union density } & $-1.240^{* *}$ & 0.610 & $1.665^{* *}$ & $1.416^{* * *}$ & $2.500^{* * *}$ & 0.454 & 0.124 \\
\hline & $(0.595)$ & $(0.704)$ & $(0.756)$ & $(0.518)$ & $(0.758)$ & $(0.898)$ & $(0.566)$ \\
\hline \multirow[t]{2}{*}{ Unemployment benefits (level) } & 0.401 & -1.329 & -0.885 & 0.658 & -0.324 & 0.631 & -0.150 \\
\hline & $(0.775)$ & $(0.918)$ & $(0.969)$ & $(0.743)$ & $(0.889)$ & $(0.955)$ & $(0.807)$ \\
\hline \multirow[t]{2}{*}{ Unemployment benefits (degression) } & 0.558 & $1.926^{* * *}$ & $1.143^{*}$ & $1.597^{* * *}$ & -0.911 & 0.848 & $1.232^{* *}$ \\
\hline & $(0.523)$ & $(0.655)$ & $(0.654)$ & $(0.477)$ & $(0.673)$ & $(0.670)$ & $(0.538)$ \\
\hline \multirow[t]{2}{*}{ Employment protection (regular) } & $-0.293^{*}$ & 0.034 & 0.023 & -0.123 & $0.649^{* * *}$ & 0.095 & $-0.337^{* *}$ \\
\hline & $(0.160)$ & $(0.180)$ & $(0.184)$ & $(0.136)$ & $(0.189)$ & $(0.197)$ & $(0.153)$ \\
\hline \multirow[t]{2}{*}{ Employment protection (temporary) } & -0.028 & 0.190 & 0.092 & $0.242^{* *}$ & -0.161 & -0.030 & 0.056 \\
\hline & $(0.097)$ & $(0.117)$ & $(0.125)$ & $(0.100)$ & $(0.116)$ & $(0.120)$ & $(0.095)$ \\
\hline$R^{2}\left(\lambda_{0}^{c}-\delta_{0}^{\complement}\right)$ & 0.780 & 0.693 & 0.674 & 0.805 & 0.713 & 0.689 & 0.797 \\
\hline Observations & 27 & 27 & 27 & 27 & 26 & 26 & 26 \\
\hline
\end{tabular}

Sample excluding survey participants from Indonesia, Ecuador, Peru, Mexico, Kazakhstan, Chile and Turkey. Fixed effects by round of data collection and minimumwage regulation not displayed. Sampling weights employed in all calculations. Standard errors in parentheses. Statistical significance at the 10,5, and 1\% level denoted by ${ }^{* * *}$, and ${ }^{* * *}$, respectively. Author's calculations based on the Survey of Adult Skills (PIAAC), the Penn World Table 9.1 (Feenstra et al. 2015), OECD statistics (https://stats.oecd.org/) and ILO statistics (https://ilostat.ilo.org/data/)
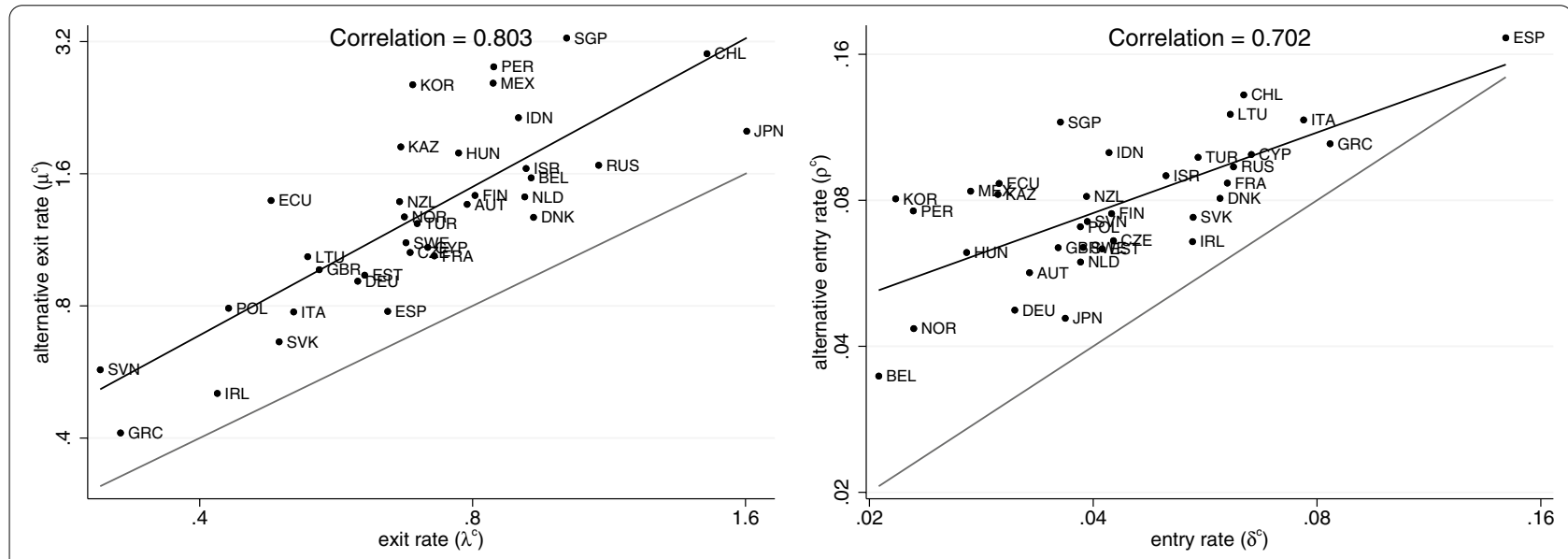

Fig. 5 Comparison of the estimated baseline transition rates with the estimated alternative transition rates. Ordinary least-squares lines (black) and 45-degree lines (gray) depicted. Sample restricted to survey participants ages 25-54. Sampling weights employed in all calculations. Author's calculations based on the Survey of Adult Skills (PIAAC), OECD statistics (https://stats.oecd.org/) and ILO statistics (https://ilostat.ilo.org/data/) 
Table 6 Country-level estimates of the effects of the displayed variables on the risks of exiting unemployment and of entering unemployment in a seemingly unrelated regressions setup à la Zellner (1962)

\begin{tabular}{|c|c|c|c|c|c|c|c|}
\hline & \multirow{3}{*}{$\begin{array}{l}\text { Monthly } \\
\text { unemployment } \\
\text { PIAAC }\end{array}$} & \multicolumn{6}{|c|}{ Out of steady state } \\
\hline & & \multicolumn{2}{|c|}{ Contemporaneous } & \multicolumn{2}{|l|}{$2011-2017$} & \multicolumn{2}{|l|}{ 2001-2019 } \\
\hline & & OECD & $\mathrm{ILO}$ & OECD & ILO & OECD & $\mathrm{ILO}$ \\
\hline & \multicolumn{7}{|c|}{$\lambda_{i}$ (log-risk of exiting unemployment) } \\
\hline \multirow[t]{2}{*}{ Numeracy (std) } & $1.022^{* * *}$ & 0.336 & 0.128 & 0.183 & -0.155 & -0.194 & -0.476 \\
\hline & $(0.354)$ & $(0.560)$ & $(0.560)$ & $(0.503)$ & $(0.515)$ & $(0.456)$ & $(0.468)$ \\
\hline \multirow[t]{2}{*}{ Logarithmized GDP per capita (PPP) } & 0.546 & -0.159 & 0.001 & -0.319 & -0.297 & -0.111 & -0.071 \\
\hline & $(0.479)$ & $(0.595)$ & $(0.595)$ & $(0.535)$ & $(0.547)$ & $(0.484)$ & $(0.497)$ \\
\hline \multirow[t]{2}{*}{ Employment in public sector (share) } & $-4.015^{* * *}$ & $-4.296^{* *}$ & $-3.969^{*}$ & $-3.405^{*}$ & -2.924 & $-3.617^{* *}$ & $-3.234^{*}$ \\
\hline & $(1.352)$ & $(2.062)$ & $(2.062)$ & $(1.852)$ & $(1.896)$ & $(1.678)$ & $(1.722)$ \\
\hline \multirow[t]{2}{*}{ ICT in the workplace (std) } & $1.104^{* *}$ & $2.680^{* * *}$ & $2.920^{* * *}$ & $2.653^{* * *}$ & $3.078^{* * *}$ & $2.316^{* * *}$ & $2.696^{* * *}$ \\
\hline & $(0.563)$ & $(0.863)$ & $(0.863)$ & $(0.775)$ & $(0.793)$ & $(0.702)$ & $(0.721)$ \\
\hline \multirow[t]{2}{*}{ Minimum relative to median wage } & 1.777 & 2.900 & 2.740 & 2.368 & 2.302 & 1.457 & 1.501 \\
\hline & $(1.155)$ & $(1.788)$ & $(1.788)$ & $(1.606)$ & $(1.643)$ & $(1.454)$ & $(1.493)$ \\
\hline \multirow[t]{2}{*}{ Trade union density } & 0.040 & 0.115 & 0.134 & -0.172 & -0.071 & 0.300 & 0.363 \\
\hline & $(0.543)$ & $(0.834)$ & $(0.834)$ & $(0.749)$ & $(0.766)$ & $(0.678)$ & $(0.696)$ \\
\hline \multirow[t]{2}{*}{ Unemployment benefits (level) } & 0.185 & -0.599 & -0.726 & -0.447 & -0.697 & -0.511 & -0.751 \\
\hline & $(0.664)$ & $(1.046)$ & $(1.046)$ & $(0.939)$ & $(0.961)$ & $(0.851)$ & $(0.873)$ \\
\hline \multirow[t]{2}{*}{ Unemployment benefits (degression) } & $1.110^{*}$ & $1.493^{* *}$ & $1.662^{* *}$ & $1.351^{* *}$ & $1.510^{* *}$ & 0.850 & $1.043^{*}$ \\
\hline & $(0.581)$ & $(0.725)$ & $(0.725)$ & $(0.651)$ & $(0.667)$ & $(0.590)$ & $(0.606)$ \\
\hline \multirow[t]{2}{*}{ Employment protection (regular) } & $-0.273^{*}$ & $-0.361^{*}$ & $-0.376^{*}$ & $-0.384^{* *}$ & $-0.359^{*}$ & $-0.401^{* *}$ & $-0.385^{* *}$ \\
\hline & $(0.166)$ & $(0.209)$ & $(0.209)$ & $(0.188)$ & $(0.192)$ & $(0.170)$ & $(0.175)$ \\
\hline \multirow[t]{2}{*}{ Employment protection (temporary) } & $0.152^{*}$ & $0.240^{*}$ & $0.252^{*}$ & 0.193 & $0.217^{*}$ & $0.191^{*}$ & $0.217^{*}$ \\
\hline & $(0.089)$ & $(0.138)$ & $(0.138)$ & $(0.124)$ & $(0.127)$ & $(0.112)$ & $(0.115)$ \\
\hline$R^{2}\left(\lambda_{0}^{C}\right)$ & 0.674 & 0.526 & 0.567 & 0.573 & 0.601 & 0.599 & 0.628 \\
\hline \multirow[t]{2}{*}{ Observations } & 25 & 27 & 27 & 27 & 27 & 27 & 27 \\
\hline & \multicolumn{7}{|c|}{$\delta_{i}($ log-risk of entering unemployment) } \\
\hline \multirow[t]{2}{*}{ Numeracy (std) } & $-1.237^{* * *}$ & $-1.294^{* * *}$ & $-1.481^{* * *}$ & $-1.254^{* * *}$ & $-1.570^{* * *}$ & $-0.789^{*}$ & $-1.069^{* *}$ \\
\hline & $(0.287)$ & $(0.400)$ & $(0.436)$ & $(0.409)$ & $(0.463)$ & $(0.446)$ & $(0.481)$ \\
\hline \multirow[t]{2}{*}{ Logarithmized GDP per capita (PPP) } & $-0.785^{* *}$ & $-0.718^{*}$ & -0.736 & -0.488 & -0.514 & -0.352 & -0.349 \\
\hline & $(0.389)$ & $(0.426)$ & $(0.463)$ & $(0.434)$ & $(0.492)$ & $(0.474)$ & $(0.511)$ \\
\hline \multirow[t]{2}{*}{ Employment in public sector (share) } & -0.804 & -1.228 & -1.119 & -1.384 & -1.059 & -0.764 & -0.488 \\
\hline & $(1.097)$ & $(1.474)$ & $(1.604)$ & $(1.505)$ & $(1.705)$ & $(1.643)$ & $(1.770)$ \\
\hline ICT in the workplace (std) & 0.322 & 0.553 & 0.877 & 0.691 & $1.270^{*}$ & 0.399 & 0.833 \\
\hline & $(0.456)$ & $(0.617)$ & $(0.671)$ & $(0.630)$ & $(0.713)$ & $(0.688)$ & $(0.741)$ \\
\hline Minimum relative to median wage & -1.041 & -0.385 & -0.433 & 0.079 & 0.096 & 0.785 & 0.831 \\
\hline & $(0.937)$ & $(1.278)$ & $(1.390)$ & $(1.305)$ & $(1.478)$ & $(1.424)$ & $(1.535)$ \\
\hline Trade union density & 0.078 & $1.207^{* *}$ & $1.327^{* *}$ & $1.371^{* *}$ & $1.429^{* *}$ & 0.895 & 0.948 \\
\hline & $(0.440)$ & $(0.596)$ & $(0.648)$ & $(0.608)$ & $(0.689)$ & $(0.664)$ & $(0.716)$ \\
\hline Unemployment benefits (level) & 0.843 & 0.163 & 0.022 & -0.272 & -0.570 & -0.418 & -0.615 \\
\hline & $(0.538)$ & $(0.747)$ & $(0.813)$ & $(0.763)$ & $(0.864)$ & $(0.833)$ & $(0.898)$ \\
\hline Unemployment benefits (degression) & -0.756 & -0.090 & -0.027 & 0.089 & 0.375 & 0.552 & 0.769 \\
\hline & $(0.471)$ & $(0.518)$ & $(0.564)$ & $(0.529)$ & $(0.599)$ & $(0.578)$ & $(0.622)$ \\
\hline Employment protection (regular) & -0.016 & $-0.298^{* *}$ & $-0.268^{*}$ & $-0.274^{*}$ & -0.243 & $-0.378^{* *}$ & $-0.375^{* *}$ \\
\hline & $(0.134)$ & $(0.150)$ & $(0.163)$ & $(0.153)$ & $(0.173)$ & $(0.167)$ & $(0.180)$ \\
\hline Employment protection (temporary) & 0.062 & 0.100 & 0.112 & $0.175^{*}$ & $0.215^{*}$ & 0.144 & 0.175 \\
\hline & $(0.072)$ & $(0.098)$ & $(0.107)$ & $(0.101)$ & $(0.114)$ & $(0.110)$ & $(0.118)$ \\
\hline$R^{2}\left(\delta_{0}^{\complement}\right)$ & 0.662 & 0.603 & 0.580 & 0.536 & 0.543 & 0.442 & 0.475 \\
\hline
\end{tabular}


Table 6 (continued)

\begin{tabular}{|c|c|c|c|c|c|c|c|}
\hline & \multirow{3}{*}{$\begin{array}{l}\text { Monthly } \\
\text { unemployment } \\
\text { PIAAC }\end{array}$} & \multicolumn{6}{|c|}{ Out of steady state } \\
\hline & & \multicolumn{2}{|c|}{ Contemporaneous } & \multicolumn{2}{|l|}{$2011-2017$} & \multicolumn{2}{|l|}{$2001-2019$} \\
\hline & & OECD & ILO & OECD & ILO & OECD & ILO \\
\hline & \multicolumn{7}{|c|}{$\lambda_{i}$ (log-risk of exiting unemployment) } \\
\hline \multirow[t]{2}{*}{ Observations } & 25 & 27 & 27 & 27 & 27 & 27 & 27 \\
\hline & \multicolumn{7}{|c|}{$\lambda_{i}-\delta_{i}$ (log-risk-ratio of exiting to entering unemployment) } \\
\hline \multirow[t]{2}{*}{ Numeracy (std) } & $2.258^{* * *}$ & $1.630^{* * *}$ & $1.609^{* * *}$ & $1.437^{* * *}$ & $1.415^{* * *}$ & $0.595^{* *}$ & $0.593^{* *}$ \\
\hline & $(0.399)$ & $(0.362)$ & $(0.357)$ & $(0.373)$ & $(0.376)$ & $(0.289)$ & $(0.292)$ \\
\hline \multirow[t]{2}{*}{ Logarithmized GDP per capita (PPP) } & $1.331^{* *}$ & 0.559 & $0.737^{*}$ & 0.169 & 0.216 & 0.242 & 0.277 \\
\hline & $(0.540)$ & $(0.385)$ & $(0.379)$ & $(0.396)$ & $(0.400)$ & $(0.308)$ & $(0.310)$ \\
\hline \multirow[t]{2}{*}{ Employment in public sector (share) } & $-3.211^{* *}$ & $-3.068^{* *}$ & $-2.850^{* *}$ & -2.021 & -1.865 & $-2.853^{* * *}$ & $-2.746^{* *}$ \\
\hline & $(1.524)$ & $(1.335)$ & $(1.314)$ & $(1.373)$ & $(1.386)$ & $(1.066)$ & $(1.074)$ \\
\hline \multirow[t]{2}{*}{ ICT in the workplace (std) } & 0.782 & $2.127^{* * *}$ & $2.043^{* * *}$ & $1.962^{* * *}$ & $1.808^{* * *}$ & $1.917^{* * *}$ & $1.863^{* * *}$ \\
\hline & $(0.634)$ & $(0.559)$ & $(0.550)$ & $(0.575)$ & $(0.580)$ & $(0.446)$ & $(0.449)$ \\
\hline \multirow[t]{2}{*}{ Minimum relative to median wage } & $2.818^{* *}$ & $3.285^{* * *}$ & $3.173^{* * *}$ & $2.289^{*}$ & $2.206^{*}$ & 0.672 & 0.670 \\
\hline & $(1.302)$ & $(1.157)$ & $(1.139)$ & $(1.191)$ & $(1.202)$ & $(0.924)$ & $(0.931)$ \\
\hline \multirow[t]{2}{*}{ Trade union density } & -0.038 & $-1.092^{* *}$ & $-1.193^{* *}$ & $-1.543^{* * *}$ & $-1.499^{* * *}$ & -0.595 & -0.585 \\
\hline & $(0.612)$ & $(0.540)$ & $(0.531)$ & $(0.555)$ & $(0.560)$ & $(0.431)$ & $(0.434)$ \\
\hline \multirow[t]{2}{*}{ Unemployment benefits (level) } & -0.658 & -0.762 & -0.748 & -0.176 & -0.127 & -0.093 & -0.136 \\
\hline & $(0.748)$ & $(0.677)$ & $(0.666)$ & $(0.696)$ & $(0.703)$ & $(0.540)$ & $(0.544)$ \\
\hline \multirow[t]{2}{*}{ Unemployment benefits (degression) } & $1.866^{* * *}$ & $1.583^{* * *}$ & $1.690^{* * *}$ & $1.262^{* * *}$ & $1.135^{* *}$ & 0.298 & 0.273 \\
\hline & $(0.654)$ & $(0.469)$ & $(0.462)$ & $(0.483)$ & $(0.487)$ & $(0.375)$ & $(0.377)$ \\
\hline \multirow[t]{2}{*}{ Employment protection (regular) } & -0.258 & -0.063 & -0.108 & -0.111 & -0.116 & -0.023 & -0.011 \\
\hline & $(0.187)$ & $(0.135)$ & $(0.133)$ & $(0.139)$ & $(0.141)$ & $(0.108)$ & $(0.109)$ \\
\hline \multirow[t]{2}{*}{ Employment protection (temporary) } & 0.091 & 0.140 & 0.140 & 0.018 & 0.002 & 0.047 & 0.042 \\
\hline & $(0.100)$ & (0.089) & $(0.088)$ & $(0.092)$ & (0.093) & $(0.071)$ & $(0.072)$ \\
\hline$R^{2}\left(\lambda_{0}^{c}-\delta_{0}^{\complement}\right)$ & 0.810 & 0.831 & 0.836 & 0.821 & 0.817 & 0.892 & 0.890 \\
\hline Observations & 25 & 27 & 27 & 27 & 27 & 27 & 27 \\
\hline
\end{tabular}

Sample restricted to survey participants ages 25-54 and excluding survey participants from Indonesia, Ecuador, Peru, Mexico, Kazakhstan, Chile and Turkey. Fixed effects by round of data collection and minimum-wage regulation not displayed. Sampling weights employed in all calculations. Standard errors in parentheses. Statistical significance at the 10,5 , and 1 percent level denoted by ${ }^{*}, * *$, and ${ }^{* * *}$, respectively. Author's calculations based on the Survey of Adult Skills (PIAAC), the Penn World Table 9.1 (Feenstra et al. 2015), OECD statistics (https://stats.oecd.org/) and ILO statistics (https://ilostat.ilo.org/data/)

estimates. Numeracy skills continue to be a key determinant of the international differences in the risk ratio of exiting to entering unemployment.

Another concern is the limited time span of the PIAAC data. The obtained effects may exclusively reflect the situation in the survey year. Therefore, I also reestimate specification (5) of Table 1 with the averages of the OECD log-risks and of the ILO logrisks in 2011-2017, respectively. The fourth and fifth specification in Table 6 display the estimates. The main conclusions are unaltered. In the sixth and in the seventh specification of Table 6, I use the longrun averages of the OECD log-risks and of the ILO log-risks in 2001-2019, respectively. The effect of numeracy skills on the risk ratio of exiting to entering unemployment remains statistically significant at the five-percent level.

In Table 7, I separately estimate the effects on the risks of exiting and entering unemployment of several additional covariates. In specification (1), a one-standard-deviation increase in literacy skills is associated with an increase in the exit rate from unemployment and with a decrease in the entry rate into unemployment by a factor of $2.4(\exp (0.869))$ and by a factor of $0.4(\exp (-1.046))$, respectively. Hence, the risk ratio of exiting to entering unemployment rises by a factor of $6.8(\exp (0.869+1.046))$. All in all, literacy skills and numeracy skills have a similar impact on the risk ratio of exiting to entering unemployment, i.e., the estimated effect does not crucially depend on the specific 
Table 7 Country-level estimates of the effects of the displayed variables on the risks of exiting unemployment and of entering unemployment in a seemingly unrelated regressions setup à la Zellner (1962)

\begin{tabular}{|c|c|c|c|c|c|c|c|}
\hline & (1) & $(2)$ & (3) & (4) & (5) & (6) & (7) \\
\hline & \multicolumn{7}{|c|}{$\lambda_{i}$ (log-risk of exiting unemployment) } \\
\hline \multirow[t]{2}{*}{ Literacy (std) } & $0.869^{* * *}$ & - & - & - & - & - & - \\
\hline & $(0.273)$ & & & & & & \\
\hline \multirow[t]{2}{*}{ Education (years) } & - & 0.069 & - & - & - & - & - \\
\hline & & $(0.068)$ & & & & & \\
\hline \multirow[t]{2}{*}{ Social trust (std) } & - & - & $0.490^{* * *}$ & - & - & - & - \\
\hline & & & $(0.165)$ & & & & \\
\hline \multirow[t]{2}{*}{ Experience (decades) } & - & - & - & -0.075 & - & - & - \\
\hline & & & & $(0.381)$ & & & \\
\hline \multirow[t]{2}{*}{ Female } & - & - & - & - & 1.678 & - & - \\
\hline & & & & & $(2.708)$ & & \\
\hline \multirow[t]{2}{*}{ Government effectiveness (std) } & - & - & - & - & - & $0.250^{* *}$ & - \\
\hline & & & & & & $(0.108)$ & \\
\hline \multirow[t]{2}{*}{ Logarithmized lagged GDP per capita (PPP) } & - & - & - & - & - & - & $0.324^{* *}$ \\
\hline & & & & & & & $(0.156)$ \\
\hline$R^{2}\left(\lambda_{0}^{c}\right)$ & 0.308 & 0.105 & 0.286 & 0.076 & 0.086 & 0.216 & 0.191 \\
\hline \multirow[t]{2}{*}{ Observations } & 30 & 30 & 30 & 30 & 30 & 30 & 30 \\
\hline & $\delta_{i}($ log-risk o & ering unem & ment) & & & & \\
\hline \multirow[t]{2}{*}{ Literacy (std) } & $-1.046^{* * *}$ & - & - & - & - & - & - \\
\hline & $(0.316)$ & & & & & & \\
\hline \multirow[t]{2}{*}{ Education (years) } & - & -0.099 & - & - & - & - & - \\
\hline & & $(0.079)$ & & & & & \\
\hline \multirow[t]{2}{*}{ Social trust (std) } & - & - & -0.339 & - & - & - & - \\
\hline & & & $(0.210)$ & & & & \\
\hline \multirow[t]{2}{*}{ Experience (decades) } & - & - & - & 0.417 & - & - & - \\
\hline & & & & $(0.439)$ & & & \\
\hline \multirow[t]{2}{*}{ Female } & - & - & - & - & 0.508 & - & - \\
\hline & & & & & $(3.182)$ & & \\
\hline \multirow[t]{2}{*}{ Government effectiveness (std) } & - & - & - & - & - & $-0.302^{* *}$ & - \\
\hline & & & & & & $(0.125)$ & \\
\hline \multirow[t]{2}{*}{ Logarithmized lagged GDP per capita (PPP) } & - & - & - & - & - & - & -0.146 \\
\hline & & & & & & & $(0.193)$ \\
\hline$R^{2}\left(\delta_{0}^{\complement}\right)$ & 0.311 & 0.107 & 0.135 & 0.087 & 0.061 & 0.214 & 0.077 \\
\hline \multirow[t]{2}{*}{ Observations } & 30 & 30 & 30 & 30 & 30 & 30 & 30 \\
\hline & $\lambda_{i}-\delta_{i}(\log$ & atio of exit & entering $u$ & bloyment) & & & \\
\hline \multirow[t]{2}{*}{ Literacy (std) } & $1.915^{* * *}$ & - & - & - & - & - & - \\
\hline & $(0.389)$ & & & & & & \\
\hline \multirow[t]{2}{*}{ Education (years) } & - & 0.167 & - & - & - & - & - \\
\hline & & $(0.110)$ & & & & & \\
\hline Social trust (std) & - & - & $0.829^{* * *}$ & - & - & - & - \\
\hline & & & $(0.271)$ & & & & \\
\hline Experience (decades) & - & - & - & -0.492 & - & - & - \\
\hline & & & & $(0.624)$ & & & \\
\hline Female & - & - & - & - & 1.169 & - & - \\
\hline & & & & & $(4.502)$ & & \\
\hline Government effectiveness (std) & - & - & - & - & - & $0.552^{* * *}$ & - \\
\hline & & & & & & $(0.165)$ & \\
\hline Logarithmized lagged GDP per capita (PPP) & - & - & - & - & - & - & $0.470^{*}$ \\
\hline & & & & & & & $(0.263)$ \\
\hline$R^{2}\left(\lambda_{0}^{c}-\delta_{0}^{c}\right)$ & 0.495 & 0.153 & 0.305 & 0.106 & 0.089 & 0.336 & 0.175 \\
\hline Observations & 30 & 30 & 30 & 30 & 30 & 30 & 30 \\
\hline
\end{tabular}


Table 7 (continued)

Sample restricted to survey participants ages 25-54 and excluding survey participants from Indonesia, Ecuador, Peru, Mexico, Kazakhstan, Chile and Turkey. Fixed effects by round of data collection not displayed. Sampling weights employed in all calculations. Standard errors in parentheses. Statistical significance at the 10, 5 , and $1 \%$ level denoted by $* * *$, and $* * *$, respectively. Author's calculations based on the Survey of Adult Skills (PIAAC), the Penn World Table 9.1 (Feenstra et al. 2015 ) and World Bank statistics (http://info.worldbank.org/governance/WGI/)

domain in which the cognitive skills are assessed. In contrast, specification (2) suggests that formal education has only limiting explanatory power. The point estimates associated with years of education are not statistically significant at conventional levels. I note that the between-country component of the variance in years of schooling and in the numeracy score account for $10.0 \%$ and for $4.4 \%$ of the respective total variance.

Social trust is the sum of the values that a person assigns to the statements "There are only a few people you can trust completely" and "If you are not careful, other people will take advantage of you," where the answer categories range from "1-Strongly agree" to "5-Strongly disagree." Notably, numerous studies document that the level of trust explains international differences in aggregate outcomes such as economic growth and institutions (e.g., Knack and Keefer 1997; Zak and Knack 2001). In specification (3) of Table 7, social trust is estimated to have a positive and significant impact on the exit rate from unemployment, suggesting that an unemployed person has better job opportunities in a trustful environment. Government effectiveness from the Worldwide Governance Indicators (WGI) captures perceptions of the quality of public services, the quality of the civil service and the degree of its independence from political pressures, the quality of policy formulation and implementation, and the credibility of the government's commitment to such policies. ${ }^{14}$ In specification (6) of Table 7, government effectiveness is estimated to be associated with a higher exit rate from unemployment and with a lower entry rate into unemployment.

In Table 8, I estimate the country-level effects of numeracy skills on the risks of exiting and of entering unemployment conditional on different sets of covariates. The effect of numeracy skills on the risk ratio of exiting to entering unemployment is statistically significant at the one-percent level in all specifications. In Table 9, I estimate the individual-level effects of numeracy skills on the risks of exiting and entering

\footnotetext{
${ }^{14}$ Accessed at http://info.worldbank.org/governance/WGI/ (WGI project) on December 20, 2020 .
}

unemployment conditional on different sets of covariates. ${ }^{15}$ The effect of numeracy skills on the risk ratio of exiting to entering unemployment is statistically significant at the onepercent level in all specifications.

Notably, education is estimated to have a positive and significant impact on the risk ratio of exiting to entering unemployment at the individual level. Furthermore, education has a substantially larger impact on the exit rate than on the entry rate. In line with these estimates, Mincer (1991) states that "the reduction of the incidence of unemployment is found to be far more important than the reduced duration of unemployment in creating the educational differentials in unemployment rates" in the Panel Study of Income Dynamics. Why is education closely related to the risk ratio of exiting to entering unemployment at the individual level but not at the country level? Important factors that relate to the formation of skills include country differences in the quality of schooling or country differences in the preschool system. However, some aspects of formal education that are not related to the formation of skills have predominantly an impact at the individual level but not necessarily at the aggregate level. For instance, insofar as signaling and rationing take place within countries but not between countries, the two mechanisms provide a rationale for the discrepancies between the individual-level and the country-level effects of education. ${ }^{16}$

\footnotetext{
15 The measure of the readiness to learn is based on the values that a person assigns to the statements "When I hear or read about new ideas, I try to relate them to real life situations to which they might apply", "I like learning new things", "When I come across something new, I try to relate it to what I already know", "I like to get to the bottom of difficult things", "I like to figure out how different ideas fit together" and "If I don't understand something, I look for additional information to make it clearer", where the five answer categories range from "Not at all" to "To a very high extent." The scale for the readiness to learn is constructed using item response theory. I standardize the learning measure to obtain a mean of zero and a standard deviation of one in the pooled international sample. I distinguish three categories of parental education: neither parent has attained upper secondary education (low), at least one parent has attained upper secondary education (medium), and at least one parent has attained tertiary education (high).

${ }^{16}$ Stijepic (2020a) documents that the employment effect of education conditional on numeracy skills tends to be more pronounced in countries with higher unemployment. A possible interpretation is that education as a rationing device for jobs, in the meaning of Collins (1979), is particularly important if jobs are scarce or, in other words, if the unemployment rate is high. Furthermore, Stijepic (2020a) finds that the average numeracy skills among individuals ages 16-19 have a significant impact on the unemployment margin of education conditional on numeracy skills in a country. A possible interpretation is that education as a signaling device for productive capacities, in the meaning of Spence (1973), is particularly important if the quality of education is high, or, in other words, if education is a good indicator of skills.
} 
Table 8 Country-level estimates of the effects of the displayed variables on the risks of exiting unemployment and of entering unemployment in a seemingly unrelated regressions setup à la Zellner (1962)

\begin{tabular}{|c|c|c|c|c|c|c|c|}
\hline & $(1)$ & (2) & (3) & (4) & (5) & (6) & (7) \\
\hline & \multicolumn{7}{|c|}{$\lambda_{i}$ (log-risk of exiting unemployment) } \\
\hline \multirow[t]{2}{*}{ Numeracy (std) } & 0.375 & $0.566^{*}$ & $0.701^{* *}$ & 0.493 & 0.564 & $0.526^{*}$ & 0.371 \\
\hline & $(0.374)$ & $(0.333)$ & $(0.284)$ & $(0.383)$ & $(0.368)$ & $(0.307)$ & $(0.265)$ \\
\hline \multirow[t]{2}{*}{ Logarithmized GDP per capita (PPP) } & - & - & - & - & 0.465 & - & -0.438 \\
\hline & & & & & $(0.394)$ & & $(0.388)$ \\
\hline \multirow[t]{2}{*}{ Employment in public sector (share) } & - & - & - & - & $-1.639^{*}$ & - & -1.422 \\
\hline & & & & & $(0.980)$ & & $(0.906)$ \\
\hline \multirow[t]{2}{*}{ ICT in the workplace (std) } & - & - & - & - & -0.071 & - & $-0.753^{* *}$ \\
\hline & & & & & $(0.486)$ & & $(0.384)$ \\
\hline \multirow[t]{2}{*}{ Minimum relative to median wage } & - & - & - & - & - & -0.547 & -0.017 \\
\hline & & & & & & $(0.966)$ & $(0.823)$ \\
\hline \multirow[t]{2}{*}{ Unemployment benefits (level) } & - & - & - & - & - & 0.144 & 0.167 \\
\hline & & & & & & $(0.502)$ & $(0.437)$ \\
\hline \multirow[t]{2}{*}{ Unemployment benefits (degression) } & - & - & - & - & - & 0.592 & $0.841^{* *}$ \\
\hline & & & & & & $(0.399)$ & $(0.354)$ \\
\hline \multirow[t]{2}{*}{ Social trust (std) } & $0.352^{*}$ & - & - & 0.267 & $0.419^{*}$ & 0.045 & 0.197 \\
\hline & $(0.213)$ & & & $(0.232)$ & $(0.244)$ & $(0.222)$ & $(0.190)$ \\
\hline \multirow[t]{2}{*}{ Government effectiveness (std) } & - & 0.151 & - & -0.068 & -0.201 & 0.336 & $0.809^{* * *}$ \\
\hline & & $(0.118)$ & & $(0.168)$ & $(0.236)$ & $(0.229)$ & $(0.242)$ \\
\hline \multirow[t]{2}{*}{ Logarithmized lagged GDP per capita (PPP) } & - & - & $0.274^{*}$ & 0.269 & 0.065 & $0.302^{*}$ & $0.359^{*}$ \\
\hline & & & $(0.144)$ & $(0.201)$ & $(0.231)$ & $(0.162)$ & $(0.198)$ \\
\hline$R^{2}\left(\lambda_{0}^{C}\right)$ & 0.309 & 0.285 & 0.328 & 0.356 & 0.430 & 0.627 & 0.743 \\
\hline \multirow[t]{2}{*}{ Observations } & 30 & 30 & 30 & 30 & 30 & 28 & 28 \\
\hline & $\delta_{i}($ log-risk & ntering uner & loyment) & & & & \\
\hline \multirow[t]{2}{*}{ Numeracy (std) } & $-1.394^{* * *}$ & $-1.022^{* * *}$ & $-1.176^{* * *}$ & $-1.257^{* * *}$ & $-1.432^{* * *}$ & $-1.513^{* * *}$ & $-1.544^{* * *}$ \\
\hline & $(0.413)$ & $(0.360)$ & $(0.319)$ & $(0.421)$ & $(0.380)$ & $(0.429)$ & $(0.381)$ \\
\hline \multirow[t]{2}{*}{ Logarithmized GDP per capita (PPP) } & - & - & - & - & -0.440 & - & $-1.063^{*}$ \\
\hline & & & & & $(0.408)$ & & $(0.558)$ \\
\hline \multirow[t]{2}{*}{ Employment in public sector (share) } & - & - & - & - & 0.626 & - & 2.048 \\
\hline & & & & & $(1.014)$ & & $(1.301)$ \\
\hline \multirow[t]{2}{*}{ ICT in the workplace (std) } & - & - & - & - & $-1.106^{* *}$ & - & $-1.171^{* *}$ \\
\hline & & & & & $(0.503)$ & & $(0.552)$ \\
\hline \multirow[t]{2}{*}{ Minimum relative to median wage } & - & - & - & - & - & $-2.693^{* *}$ & $-2.713^{* *}$ \\
\hline & & & & & & $(1.350)$ & $(1.183)$ \\
\hline \multirow[t]{2}{*}{ Unemployment benefits (level) } & - & - & - & - & - & 0.921 & 0.584 \\
\hline & & & & & & $(0.702)$ & $(0.628)$ \\
\hline \multirow[t]{2}{*}{ Unemployment benefits (degression) } & - & - & - & - & - & -0.878 & -0.415 \\
\hline & & & & & & $(0.558)$ & $(0.509)$ \\
\hline \multirow[t]{2}{*}{ Social trust (std) } & 0.176 & - & - & 0.347 & 0.383 & 0.099 & 0.170 \\
\hline & $(0.235)$ & & & $(0.255)$ & $(0.252)$ & $(0.311)$ & $(0.274)$ \\
\hline \multirow[t]{2}{*}{ Government effectiveness (std) } & - & -0.123 & - & -0.252 & 0.267 & -0.145 & 0.454 \\
\hline & & $(0.128)$ & & $(0.184)$ & $(0.244)$ & $(0.320)$ & $(0.347)$ \\
\hline Logarithmized lagged GDP per capita (PPP) & - & - & -0.063 & 0.077 & 0.220 & -0.007 & $0.500^{*}$ \\
\hline & & & $(0.162)$ & $(0.221)$ & $(0.239)$ & $(0.226)$ & $(0.284)$ \\
\hline$R^{2}\left(\delta_{0}^{\complement}\right)$ & 0.373 & 0.380 & 0.364 & 0.420 & 0.545 & 0.499 & 0.635 \\
\hline Observations & 30 & 30 & 30 & 30 & 30 & 28 & 28 \\
\hline & $\lambda_{i}-\delta_{i}(\log$ & k-ratio of exit & to entering & employmen & & & \\
\hline Numeracy (std) & $1.770^{* * *}$ & $1.588^{* * *}$ & $1.877^{* * *}$ & $1.751^{* * *}$ & $1.996^{* * *}$ & $2.039^{* * *}$ & $1.915^{* * *}$ \\
\hline
\end{tabular}


Table 8 (continued)

\begin{tabular}{|c|c|c|c|c|c|c|c|}
\hline & $(1)$ & (2) & (3) & (4) & (5) & (6) & (7) \\
\hline & $(0.535)$ & $(0.450)$ & $(0.395)$ & $(0.540)$ & $(0.472)$ & $(0.450)$ & $(0.424)$ \\
\hline \multirow[t]{2}{*}{ Logarithmized GDP per capita (PPP) } & - & - & - & - & $0.905^{*}$ & - & 0.626 \\
\hline & & & & & $(0.505)$ & & $(0.621)$ \\
\hline \multirow[t]{2}{*}{ Employment in public sector (share) } & - & - & - & - & $-2.265^{*}$ & - & $-3.470^{* *}$ \\
\hline & & & & & $(1.258)$ & & $(1.448)$ \\
\hline \multirow[t]{2}{*}{ ICT in the workplace (std) } & - & - & - & - & $1.034^{*}$ & - & 0.418 \\
\hline & & & & & $(0.624)$ & & $(0.614)$ \\
\hline \multirow[t]{2}{*}{ Minimum relative to median wage } & - & - & - & - & - & 2.146 & $2.696 * *$ \\
\hline & & & & & & $(1.418)$ & $(1.316)$ \\
\hline \multirow[t]{2}{*}{ Unemployment benefits (level) } & - & - & - & - & - & -0.777 & -0.417 \\
\hline & & & & & & $(0.737)$ & $(0.699)$ \\
\hline \multirow[t]{2}{*}{ Unemployment benefits (degression) } & - & - & - & - & - & $1.470^{* *}$ & $1.256^{* *}$ \\
\hline & & & & & & $(0.586)$ & $(0.567)$ \\
\hline \multirow[t]{2}{*}{ Social trust (std) } & 0.175 & - & - & -0.080 & 0.036 & -0.054 & 0.027 \\
\hline & $(0.305)$ & & & $(0.326)$ & $(0.313)$ & $(0.326)$ & $(0.304)$ \\
\hline \multirow[t]{2}{*}{ Government effectiveness (std) } & - & $0.273^{*}$ & - & 0.184 & -0.467 & 0.480 & 0.355 \\
\hline & & $(0.159)$ & & $(0.236)$ & $(0.302)$ & $(0.336)$ & $(0.387)$ \\
\hline \multirow[t]{2}{*}{ Logarithmized lagged GDP per capita (PPP) } & - & - & $0.337^{*}$ & 0.192 & -0.154 & 0.309 & -0.141 \\
\hline & & & $(0.201)$ & $(0.283)$ & $(0.297)$ & $(0.238)$ & $(0.316)$ \\
\hline$R^{2}\left(\lambda_{0}^{c}-\delta_{0}^{\complement}\right)$ & 0.491 & 0.531 & 0.529 & 0.539 & 0.662 & 0.730 & 0.779 \\
\hline Observations & 30 & 30 & 30 & 30 & 30 & 28 & 28 \\
\hline
\end{tabular}

Sample restricted to survey participants ages 25-54 and excluding survey participants from Indonesia, Ecuador, Peru, Mexico, Kazakhstan, Chile and Turkey. Fixed effects by round of data collection not displayed. Set of covariates in specifications (6), (7) additionally includes an indicator variable for countries without minimumwage regulations. Sampling weights employed in all calculations. Standard errors in parentheses. Statistical significance at the 10,5, and $1 \%$ level denoted by ${ }^{* * *}$, and ***, respectively. Author's calculations based on the Survey of Adult Skills (PIAAC), the Penn World Table 9.1 (Feenstra et al. 2015), OECD statistics (https://stats.oecd. org/) and World Bank statistics (http://info.worldbank.org/governance/WGI/)

Social trust is estimated to raise the risk ratio of exiting to entering unemployment at the individual level. The increase in the risk ratio is almost exclusively explained by the reduction in the risk of entering unemployment. In contrast, social trust tends to be predominantly associated with a higher exit rate from unemployment at the country level. The discrepancies between the country-level and the individual-level effects of social trust potentially reflect the different channels through which social trust affects economic outcomes: An unemployed person's job prospects may depend on the trust of other people, in particular, the trust of employers. A trusting employed person may enjoy stable employment by forming closer relationships with colleagues.

All the three human-capital measures, i.e., numeracy skills, education and social trust, seem to play an important role in determining the risk ratio of exiting to entering unemployment at the individual level. In contrast, numeracy skills are the dominant factor at the country level. Notably, years spent in education, numeracy skills and social trust all sizably reduce the risk of entering unemployment at the individual level. However, only numeracy skills have a sizable and statistically significant impact on the exit rate from unemployment. 
Table 9 Individual-level maximum-likelihood estimates of the effects of the displayed variables on the risks of exiting unemployment and of entering unemployment. Sample restricted to survey participants ages 25-54. Fixed effects by country not displayed

\begin{tabular}{|c|c|c|c|c|c|c|c|}
\hline & $(1)$ & $(2)$ & (3) & $(4)$ & (5) & (6) & (7) \\
\hline & \multicolumn{7}{|c|}{$\lambda_{i}$ (log-risk of exiting unemployment) } \\
\hline \multirow[t]{2}{*}{ Numeracy (std) } & $0.174^{* * *}$ & $0.168^{* * *}$ & $0.165^{* * *}$ & $0.162^{* * *}$ & $0.154^{* * *}$ & $0.163^{* * *}$ & $0.125^{* * *}$ \\
\hline & $(0.029)$ & $(0.030)$ & $(0.027)$ & $(0.029)$ & $(0.028)$ & $(0.032)$ & $(0.032)$ \\
\hline \multirow[t]{2}{*}{ Social trust (std) } & 0.024 & - & - & 0.024 & - & - & 0.021 \\
\hline & $(0.020)$ & & & $(0.019)$ & & & $(0.022)$ \\
\hline \multirow[t]{2}{*}{ Readiness to learn (std) } & - & 0.021 & - & 0.019 & - & - & 0.021 \\
\hline & & $(0.022)$ & & $(0.023)$ & & & $(0.024)$ \\
\hline \multirow[t]{2}{*}{ Education (years) } & - & - & 0.007 & 0.006 & - & - & 0.011 \\
\hline & & & $(0.009)$ & $(0.009)$ & & & $(0.010)$ \\
\hline \multirow[t]{2}{*}{ Experience (decades) } & -0.009 & 0.011 & 0.017 & 0.006 & -0.011 & -0.001 & -0.012 \\
\hline & $(0.080)$ & $(0.081)$ & $(0.083)$ & $(0.081)$ & $(0.082)$ & $(0.082)$ & $(0.083)$ \\
\hline \multirow[t]{2}{*}{ Experience $^{2}$ (decades) } & -0.011 & -0.016 & -0.016 & -0.012 & -0.009 & -0.017 & -0.008 \\
\hline & $(0.020)$ & $(0.020)$ & $(0.020)$ & $(0.020)$ & $(0.021)$ & $(0.021)$ & $(0.022)$ \\
\hline \multirow[t]{2}{*}{ Medium parental education } & - & - & - & - & $0.094^{*}$ & - & $0.093^{*}$ \\
\hline & & & & & $(0.053)$ & & $(0.055)$ \\
\hline \multirow[t]{2}{*}{ High parental education } & - & - & - & - & 0.040 & - & 0.039 \\
\hline & & & & & $(0.070)$ & & $(0.073)$ \\
\hline \multirow[t]{2}{*}{ Female } & - & - & - & - & - & $-0.275^{* * *}$ & $-0.272^{* * *}$ \\
\hline & & & & & & $(0.044)$ & $(0.047)$ \\
\hline \multirow[t]{2}{*}{ Native } & - & - & - & - & - & 0.045 & 0.041 \\
\hline & & & & & & $(0.074)$ & $(0.073)$ \\
\hline Log-likelihood & $-29,453$ & $-30,266$ & $-29,952$ & $-29,170$ & $-28,237$ & $-30,166$ & $-27,113$ \\
\hline Countries & 36 & 37 & 37 & 36 & 37 & 37 & 36 \\
\hline \multirow[t]{2}{*}{ Observations } & 113,725 & 115,998 & 115,885 & 113,612 & 110,553 & 115,934 & 108,279 \\
\hline & $\delta_{i}($ log-risk & ering unemp & hent) & & & & \\
\hline \multirow[t]{2}{*}{ Numeracy (std) } & $-0.307^{* * *}$ & $-0.335^{* * *}$ & $-0.195^{* * *}$ & $-0.189^{* * *}$ & $-0.341^{* * *}$ & $-0.316^{* * *}$ & $-0.179^{* * *}$ \\
\hline & $(0.041)$ & $(0.043)$ & $(0.046)$ & $(0.046)$ & $(0.042)$ & $(0.044)$ & $(0.051)$ \\
\hline \multirow[t]{2}{*}{ Social trust (std) } & $-0.172^{* * *}$ & - & - & $-0.137^{* * *}$ & - & - & $-0.130^{* * *}$ \\
\hline & $(0.032)$ & & & $(0.034)$ & & & $(0.037)$ \\
\hline \multirow[t]{2}{*}{ Readiness to learn (std) } & - & 0.010 & - & $0.052^{* *}$ & - & - & $0.049^{*}$ \\
\hline & & $(0.025)$ & & $(0.025)$ & & & $(0.027)$ \\
\hline \multirow[t]{2}{*}{ Education (years) } & - & - & $-0.118^{* * *}$ & $-0.115^{* * *}$ & - & - & $-0.118^{* * *}$ \\
\hline & & & $(0.013)$ & $(0.014)$ & & & $(0.014)$ \\
\hline \multirow[t]{2}{*}{ Experience (decades) } & $-0.494^{* * *}$ & $-0.456^{* * *}$ & $-0.598^{* * *}$ & $-0.617^{* * *}$ & $-0.517^{* * *}$ & $-0.463^{* * *}$ & $-0.659^{* * *}$ \\
\hline & $(0.104)$ & $(0.104)$ & $(0.106)$ & $(0.105)$ & $(0.109)$ & $(0.101)$ & $(0.102)$ \\
\hline \multirow[t]{2}{*}{ Experience $^{2}$ (decades) } & $0.070^{* * *}$ & $0.062^{* *}$ & $0.063^{* *}$ & $0.069^{* * *}$ & $0.080^{* * *}$ & $0.062^{* *}$ & $0.085^{* * *}$ \\
\hline & $(0.026)$ & $(0.025)$ & $(0.025)$ & $(0.025)$ & $(0.026)$ & $(0.025)$ & $(0.025)$ \\
\hline \multirow[t]{2}{*}{ Medium parental education } & - & - & - & - & 0.055 & - & $0.141^{* *}$ \\
\hline & & & & & $(0.066)$ & & $(0.071)$ \\
\hline \multirow[t]{2}{*}{ High parental education } & - & - & - & - & -0.038 & - & $0.120^{*}$ \\
\hline & & & & & $(0.065)$ & & $(0.063)$ \\
\hline \multirow[t]{2}{*}{ Female } & - & - & - & - & - & $-0.131^{*}$ & -0.045 \\
\hline & & & & & & $(0.069)$ & $(0.073)$ \\
\hline Native & - & - & - & - & - & $-0.251^{* *}$ & $-0.326^{* * *}$ \\
\hline & & & & & & $(0.101)$ & $(0.103)$ \\
\hline Log-likelihood & $-29,453$ & $-30,266$ & $-29,952$ & $-29,170$ & $-28,237$ & $-30,166$ & $-27,113$ \\
\hline Countries & 36 & 37 & 37 & 36 & 37 & 37 & 36 \\
\hline Observations & 113,725 & 115,998 & 115,885 & 113,612 & 110,553 & 115,934 & 108,279 \\
\hline
\end{tabular}


Table 9 (continued)

\section{(1)}

$(2)$

\begin{tabular}{|c|c|c|c|c|c|c|c|}
\hline \multirow{3}{*}{ Numeracy (std) } & \multicolumn{7}{|c|}{$\lambda_{i}-\delta_{i}$ (log-risk-ratio of exiting to entering unemployment) } \\
\hline & $0.480^{* * *}$ & $0.503^{* * *}$ & $0.360^{* * *}$ & $0.351^{* * *}$ & $0.495^{* * *}$ & $0.479 * * *$ & $0.305^{* * *}$ \\
\hline & $(0.038)$ & $(0.039)$ & $(0.042)$ & $(0.042)$ & $(0.039)$ & $(0.037)$ & $(0.042)$ \\
\hline \multirow[t]{2}{*}{ Social trust (std) } & $0.196^{* * *}$ & - & - & $0.161^{* * *}$ & - & - & $0.151^{* * *}$ \\
\hline & $(0.019)$ & & & $(0.021)$ & & & $(0.021)$ \\
\hline \multirow[t]{2}{*}{ Readiness to learn (std) } & - & 0.011 & - & -0.033 & - & - & -0.028 \\
\hline & & $(0.026)$ & & $(0.026)$ & & & $(0.027)$ \\
\hline \multirow[t]{2}{*}{ Education (years) } & - & - & $0.125^{* * *}$ & $0.122^{* * *}$ & - & - & $0.130^{* * *}$ \\
\hline & & & $(0.014)$ & $(0.014)$ & & & $(0.014)$ \\
\hline \multirow[t]{2}{*}{ Experience (decades) } & $0.485^{* * *}$ & $0.467^{* * *}$ & $0.615^{* * *}$ & $0.623^{* * *}$ & $0.506^{* * *}$ & $0.461^{* * *}$ & $0.648^{* * *}$ \\
\hline & $(0.072)$ & $(0.070)$ & $(0.065)$ & $(0.068)$ & $(0.074)$ & $(0.070)$ & $(0.068)$ \\
\hline \multirow[t]{2}{*}{ Experience $^{2}$ (decades) } & $-0.081^{* * *}$ & $-0.078^{* * *}$ & $-0.079^{* * *}$ & $-0.082^{* * *}$ & $-0.089^{* * *}$ & $-0.079^{* * *}$ & $-0.093^{* * *}$ \\
\hline & $(0.017)$ & $(0.016)$ & $(0.016)$ & $(0.016)$ & $(0.017)$ & $(0.017)$ & $(0.017)$ \\
\hline \multirow[t]{2}{*}{ Medium parental education } & - & - & - & - & 0.039 & - & -0.048 \\
\hline & & & & & $(0.048)$ & & $(0.049)$ \\
\hline \multirow[t]{2}{*}{ High parental education } & - & - & - & - & $0.078^{*}$ & - & $-0.081^{*}$ \\
\hline & & & & & $(0.046)$ & & $(0.047)$ \\
\hline \multirow[t]{2}{*}{ Female } & - & - & - & - & - & $-0.144^{* *}$ & $-0.227^{* * *}$ \\
\hline & & & & & & $(0.064)$ & $(0.064)$ \\
\hline \multirow[t]{2}{*}{ Native } & - & - & - & - & - & $0.295^{* * *}$ & $0.367^{* * *}$ \\
\hline & & & & & & $(0.066)$ & $(0.063)$ \\
\hline Log-likelihood & $-29,453$ & $-30,266$ & $-29,952$ & $-29,170$ & $-28,237$ & $-30,166$ & $-27,113$ \\
\hline Countries & 36 & 37 & 37 & 36 & 37 & 37 & 36 \\
\hline Observations & 113,725 & 115,998 & 115,885 & 113,612 & 110,553 & 115,934 & 108,279 \\
\hline
\end{tabular}

Sampling weights employed in all calculations, giving the same weight to each country. Robust standard errors in parentheses, adjusted for clustering at the country level. Statistical significance at the 10,5 , and $1 \%$ level denoted by ${ }^{*},{ }^{*}$, and ${ }^{* * *}$, respectively. Author's calculations based on the Survey of Adult Skills (PIAAC)

\section{Acknowlegements}

I thank Martin Biewen, Denis Stijepic, Francis Teal, Klaus Wälde, two anonymous referees, and the participants of the Chair in Macroeconomics Research Day at the Johannes Gutenberg University (Mainz, 2016) and the Annual Conference of the European Association of Labour Economists (St. Gallen, 2017) for helpful comments. I gratefully acknowledge the financial support provided by the Fritz Thyssen Foundation under the Grant No. 40.16.0.028WW and by the German Research Foundation (DFG) under the Grant No. 433336278. The usual disclaimer applies.

\section{Authors' contributions}

The author read and approved the final manuscript.

Received: 24 September 2020 Accepted: 4 February 2021

Published online: 27 March 2021

\section{References}

Acemoglu, D., Johnson, S., Robinson, J.A.: The colonial origins of comparative development: An empirical investigation. American Economic Review 91(5), 1369-1401 (2001)

Acemoglu, D., Johnson, S., Robinson, J.A.: Institutions as a Fundamental Cause of Long-Run Growth. In: Aghion, P., Durlauf, S. (eds.) Handbook of Economic Growth. Vol 1 of Handbook of Economic Growth, pp. 385-472. Elsevier, New York (2005)
Arpaia, A., Mourre, G.: Institutions and performance in European Labour markets: Taking a fresh look at evidence. Journal of Economic Surveys 26(1), 1-41 (2012)

Becker, G.S.: Human capital: A theoretical and empirical analysis with special reference to education. Columbia University Press, Columbia (1964)

Belot, M., van Ours, J.C.: Does the recent success of some OECD countries in lowering their unemployment rates lie in the clever design of their labor market reforms? Oxford Economic Papers 56(4), 621-642 (2004)

Bentolila, S., Cahuc, P., Dolado, J.J., Barbanchon, T.L.: Two-tier labour markets in the Great Recession: France versus Spain. Economic Journal 122(562), F155-F187 (2012)

Bertola, G., Rogerson, R.: Institutions and labor reallocation. European Economic Review 41(6), 1147-1171 (1997)

Bick, A., Fuchs-Schündeln, N., Lagakos, D.: How do hours worked vary with income? Cross-country evidence and implications. American Economic Review 108(1), 170-199 (2018)

Blanchard, O., Portugal, P.: What hides behind an unemployment rate: Comparing Portuguese and U.S. Labor Markets. American Economic Review 91(1), 187-207 (2001)

Blanchard, O.J., Summers, L.H.: Hysteresis and the European Unemployment Problem. In: Chapters, N.B.E.R. (ed.) NBER Macroeconomics Annual 1986, vol. 1, pp. 15-90. National Bureau of Economic Research Inc (1986)

Boeri, T., Conde-Ruiz, J.I., Galasso, V.: The political economy of flexicurity. Journal of the European Economic Association 10(4), 684-715 (2012)

Bowman, M.J.: The human investment revolution in economic thought. Sociology of Education 39(2), 111-137 (1966)

Collins, R.: The credential society: An historical sociology of education and stratification. Academic Press, New York (1979) 
Edin, P.-A., Gustavsson, M.: Time out of work and skill depreciation. ILR Review 61(2), 163-180 (2008)

Eliason, M.: Lost jobs, broken marriages. Journal of Population Economics 25(4), 1365-1397 (2012)

Elsby, M.W.L., Hobijn, B., Sahin, A.: Unemployment dynamics in the OECD. The Review of Economics and Statistics 95(2), 530-548 (2013)

Feenstra, R.C., Inklaar, R., Timmer, M.P.: The next generation of the Penn World Table. American Economic Review 105(10), 3150-3182 (2015)

Fougère, D., Kramarz, F., Pouget, J.: Youth unemployment and crime in France. Journal of the European Economic Association 7(5), 909-938 (2009)

Hanushek, E., Woessmann, L.: Do better schools lead to more growth? Cognitive skills, economic outcomes, and causation. Journal of Economic Growth 17(4), 267-321 (2012)

Hanushek, E.A., Kimko, D.D.: Schooling, labor-force quality, and the growth of nations. American Economic Review 90(5), 1184-1208 (2000)

Hanushek, E.A., Schwerdt, G., Wiederhold, S., Woessmann, L.: Returns to skills around the world: Evidence from PIAAC. European Economic Review 73(3), 103-130 (2015)

Hanushek, E.A., Schwerdt, G., Wiederhold, S., Woessmann, L.: Coping with change: International differences in the returns to skills. Economics Letters 153, 15-19 (2017)

Hanushek, E.A., Woessmann, L.: The role of cognitive skills in economic development. Journal of Economic Literature 46(3), 607-68 (2008)

Hanushek, E.A., Woessmann, L.: The Economics of International Differences in Educational Achievement. Vol. 3 of Handbook of the Economics of Education. Elsevier 2, 89-200 (2011)

Heckman, J.J., Kautz, T.: Hard evidence on soft skills. Labour Economics 19(4), 451-464 (2012)

Hidalgo-Cabrillana, A., Kuehn, Z., Lopez-Mayan, C.: Development accounting using PIAAC data. SERIEs Journal of the Spanish Economic Association 8(4), 373-399 (2017)

Iversen, J.M.V., Strøm, B.: Skills, employment, and labor market institutions: Evidence from PIAAC. LABOUR 34(3), 277-304 (2020)

Kaitz, H.B.: Analyzing the length of spells of unemployment. Monthly Labor Review 93(11), 11-20 (1970)

Knack, S., Keefer, P.: Does social capital have an economic payoff? A crosscountry investigation. The Quarterly Journal of Economics 112(4) 1251-1288 (1997)

Kuhn, A., Lalive, R., Zweimueller, J.: The Public Health Costs of Job Loss. Journal of Health Economics 28(6), 1099-1115 (2009)

Launov, A., Wälde, K.: The employment effect of reforming a public employment agency. European Economic Review 84(3), 140-164 (2016)

Leuven, E., Oosterbeek, H., van Ophem, H.: Explaining international differences in male skill wage differentials by differences in demand and supply of skill. Economic Journal 114(495), 466-486 (2004)
Medina, L., Schneider, F.: Shadow Economies Around the World: What Did We Learn Over the Last 20 Years? IMF Working Papers 2018/017, International Monetary Fund (2018)

Mincer, J.: Education and Unemployment. NBER Working Papers 3838, National Bureau of Economic Research, Inc (1991)

Mincer, J.A.: Schooling, Experience, and Earnings. NBER Books, National Bureau of Economic Research Inc. London (1974)

Nickell, S., Layard, R.: Labor market institutions and economic performance. In: Ashenfelter, O., Card, D. (Eds), Handbook of Labor Economics Vol 3 of Handbook of Labor Economics. New York: Elsevier, pp. 3029-3084

OECD. Technical Report of the Survey of Adult Skills (PIAAC), 2nd edn. OECD Publishing, Paris (2016)

Shimer, R.: Reassessing the Ins and Outs of Unemployment. Review of Economic Dynamics 15(2), 127-148 (2012)

Spence, M.: Job Market Signaling. The Quarterly Journal of Economics 87(3), 355-374 (1973)

Stijepic, D.: Small employers, large employers and the skill premium. Economics Bulletin 36(1), 381-387 (2016)

Stijepic, D.: Globalization, worker mobility and wage inequality. Review of International Economics 25(1), 108-131 (2017)

Stijepic, D:: The impact of the productivity dispersion across employers on the labor's income share. Economics Bulletin 39(1), 73-83 (2019)

Stijepic, D.: Employment effects of skills around the world: Evidence from the PIAAC. International Labour Review 159(3), 307-338 (2020a)

Stijepic, D.: Job Mobility and Sorting: Theory and Evidence. Journal of Economics and Statistics 240(1), 19-49 (2020b)

Stijepic, D.: Trends and cycles in U.S. job mobility. The Manchester School 89(2), 203-222 (2021)

Sullivan, D., von Wachter, T.: Job displacement and mortality: An analysis using administrative data. The Quarterly Journal of Economics 124(3), 1265-1306 (2009)

Zak, P.J., Knack, S.: Trust and Growth. Economic Journal 111(470), 295-321 (2001)

Zellner, A.: An Efficient Method of Estimating Seemingly Unrelated Regressions and Tests for Aggregation Bias. Journal of the American Statistical Association 57(298), 348-368 (1962)

\section{Publisher's Note}

Springer Nature remains neutral with regard to jurisdictional claims in published maps and institutional affiliations.

\section{Submit your manuscript to a SpringerOpen ${ }^{\circ}$ journal and benefit from:}

- Convenient online submission

$\checkmark$ Rigorous peer review

- Open access: articles freely available online

- High visibility within the field

- Retaining the copyright to your article

Submit your next manuscript at $\boldsymbol{\nabla}$ springeropen.com 